\title{
Teorias biológicas do envelhecimento
}

\author{
M. Paula Mota ${ }^{1}$ \\ Pedro A. Figueiredo ${ }^{2}$ \\ José A. Duarte ${ }^{3}$
}

https://doi.org/10.5628/rpcd.04.01.81

\author{
${ }^{1}$ Departamento de Desporto, Universidade de Trás-os- \\ -Montes e Alto Douro \\ ${ }^{2}$ Instituto Superior da Maia \\ ${ }^{3}$ Faculdade de Ciências do Desporto e de Educação Física \\ Universidade do Porto, Portugal
}

\section{ABSTRACT \\ Biological Theories of Aging}

Da interacção entre o genoma e os factores estocásticos resulta a maior ou menor velocidade de envelhecimento do organismo. Se a capacidade de adaptação do organismo for reduzida e/ou se a acção dos factores estocásticos for exagerada, o resultado poderá ser um desequilíbrio excessivo que aumentará a susceptibilidade para acumular lesões e défices celulares, manifestando-se no fenómeno de envelhecimento celular, tecidular e orgânico. A compreensão deste fenómeno passa pelo conhecimento dos mecanismos biológicos específicos subjacentes aos desequilíbrios que causam a perda de funcionalidade progressiva com a idade, com o consequente aumento da susceptibilidade $e$ incidência de doenças, aumentando a probabilidade de morte. O interesse despertado por esta temática levou ao desenvolvimento de múltiplas teorias biológicas do envelhecimento, mais centradas na importância dos factores genéticos ou nos factores estocásticos, sendo as mais conhecidas descritas neste trabalho.

Palavras-chave: envelhecimento biológico, teorias estocásticas, teorias genéticas.
Aging rate is the result of genomic and stochastic factors interactions. If organic capacity to face the insults of stochastic factors is insufficient, cell imbalance should income leading to increase susceptibility to accumulate damage, which is patent on cell, tissue and organic aging phenomenon. To understand this phenomenon it's necessary to recogni$z$ e the specific biologic mechanisms that underlie these imbalances, and that lead to the progressive age-related deterioration in function, causing an increase in susceptibility to disease, and thereby enhancing the risk of death. Related interest on this problem encourages the development of several biologic theories of aging, some of them supported on genetic factors, and the others focused on the stochastic mechanisms. Some of the most popular biological theories of aging will be reviewed in this paper.

Key Words: aging biology, stocastic theories, genetic theories. 


\section{INTRODUÇÃO}

Para além do nascimento e da morte, uma das certezas da vida é que todas as pessoas envelhecem. No entanto, a manifestação do fenómeno de envelhecimento ao longo da vida é variável entre os indivíduos da mesma espécie e entre indivíduos de espécies diferentes. Esta constatação deu origem ao desenvolvimento de inúmeras definições de envelhecimento biológico que, apesar de divergirem na orientação teórica subjacente, comungam a noção de perda de funcionalidade progressiva com a idade, com o consequente aumento da susceptibilidade e incidência de doenças, aumentando a probabilidade de morte. Da interacção entre o genoma e os factores estocásticos resulta a maior ou menor velocidade de envelhecimento do organismo. Se a capacidade de adaptação do organismo for reduzida e/ou se a acção dos factores estocásticos for exagerada, o resultado poderá ser um desequilíbrio excessivo, que aumentará a susceptibilidade para acumular lesões e défices celulares, manifestando-se no fenómeno de envelhecimento celular, tecidular e orgânico. A compreensão do fenómeno de envelhecimento passa pelo conhecimento dos mecanismos biológicos específicos subjacentes a estes desequilíbrios. A curiosidade despertada por este problema tem sido de tal forma explorada que, em 2000, Medvedev recenseou mais de 300 teorias desde o século XVIII (154). Tendo por base as diferenças de longevidade entre as espécies animais $(45,61,235)$, assim como a identificação de genes específicos responsáveis pela redução significativa do tempo de vida, como ocorre nas síndromes de Werner e Progéria $(67,83,149)$, diversos investigadores sugerem que a velocidade do fenómeno de envelhecimento é condicionada por factores genéti$\cos (79,80,96)$. No entanto, apesar da importância atribuída aos factores genéticos, os factores estocásticos também poderão ser determinantes para a longevidade. Com efeito, diversas situações experimentais (por exemplo, ambientes hipertérmicos ou de hipóxia, radiações ionizantes, manipulação calórica) têm demonstrado a capacidade dos factores exógenos em modificar o fenómeno de envelhecimento em diversas espécies, tais como em Caernohabiditis elegans (141), em Drosophila melanogaster (146, 181, 232) e em ratos (101).
Das diversas teorias do envelhecimento muitas delas estão obsoletas, sendo as restantes ainda demasiado numerosas para serem abordadas individualmente. Porém, podem ser operacionalmente divididas em duas categorias gerais: Teorias Genéticas e Teorias Estocásticas.

\section{TEORIAS GENÉTICAS}

Sem negar a importância das influências ambientais na longevidade, os biogerontologistas salientam a determinante participação dos genes neste fenómeno.

\section{Teoria da Velocidade de Vida}

A "Teoria da Velocidade de Vida" foi proposta por Pearl (188) e advoga que a longevidade é inversamente proporcional à taxa metabólica.

Anteriormente, Rubner (para ref. ver 188) explicara as diferenças de longevidade entre as espécies de mamíferos com base na desigualdade de dispêndio energético por grama de tecido. Ou seja, as características genéticas de cada espécie de mamíferos determinariam a sua taxa metabólica e, deste modo, a sua maior ou menor longevidade comparativamente às outras espécies. Os trabalhos desenvolvidos por Loeb e Northrop $(143,144)$ demonstraram que o tempo de vida era inversamente proporcional à temperatura ambiente em Drosophilas melanogaster, diminuindo aproximadamente 10 vezes entre os $10^{\circ} \mathrm{C} \mathrm{e}$ os $30^{\circ} \mathrm{C}$. As variações na temperatura tiveram efeitos semelhantes durante a fase de larva, pupa e mosca adulta. Para Pearl (1938), este facto parecia reforçar o pressuposto da existência de uma capacidade de produzir energia pré-definida geneticamente, finda a qual os animais morreriam. Neste sentido, a sujeição das Drosophilas a temperaturas elevadas terá aumentado a taxa metabólica, provocando um esgotamento rápido da capacidade de produzir energia, considerada limitada geneticamente, pelo que a mortalidade terá aumentado.

Mais tarde, as diferenças na longevidade entre as espécies foi explicada pelo facto dos animais de menores dimensões terem, normalmente, um metabolismo basal mais elevado e menor tempo de vida $(44,235)$. Foram elaboradas diversas equações matemáticas, descritas por Finch (61), com o intuito de estabelecer uma relação entre as dimensões do corpo e a longevidade. No entanto, não é difícil encontrar 
inúmeras "excepções" a esta regra entre animais do mesmo filo. Por exemplo, entre os mamíferos, o caso mais flagrante é o do morcego, cuja longevidade é semelhante à do cavalo, apesar da enorme diferença de tamanho. A "Teoria da Velocidade de Vida" foi sendo sucessivamente reformulada até que Sacher (209) propôs uma nova equação matemática que considerava diversos índices metabólicos (tamanho do cérebro, tamanho do corpo, consumo de oxigénio por minuto e temperatura corporal) e que estabelecia uma relação entre a longevidade e a actividade metabólica das diversas espécies animais:

$$
L=0.66 E^{0.6} M^{-0.4} P^{-0.5} T^{0.25}
$$

\section{[Lé o tempo máximo de vida (anos], Eé o peso do cérebro (g), M é o peso do corpo ( $g$ ), Pé o metabolismo basal em repouso ( $\mathrm{mL} . \mathrm{kg}$-1 . min-1) e Té a temperatura corporal $\left.\left({ }^{\circ} \mathrm{C}\right)\right]$.}

De acordo com esta equação, o factor temperatura corporal é o que menos contribui para as diferenças na longevidade entre as espécies animais. Este dado levanta algumas questões relativamente às tendências inicialmente propostas por Pearl, que considerava que a longevidade das Drosophilas melanogaster era afectada pela temperatura (para ref. ver 61). De facto, o problema do aumento do metabolismo com a temperatura ambiente foi mais tarde estudado por Arking et al. (8), que utilizaram o consumo de oxigénio como indicador metabólico, em quatro linhas diferentes de Drosophilas melanogaster. Os resultados deste estudo demonstraram que o metabolismo difere com a linha estudada e que a sua variação induzida pela temperatura ambiente não é igual nas diferentes linhas. Considerando este indicador metabólico, o autor constatou que o metabolismo basal não influencia a longevidade das Drosophilas melanogaster. A análise da equação proposta por Sacher (209) revela pouca clareza na relação entre o metabolismo basal, as dimensões corporais e a longevidade entre animais da mesma espécie. Por exemplo, tem sido demonstrado que a restrição calórica influencia positivamente a longevidade de ratinhos sem, contudo, se verificarem alterações no metabolismo basal por grama de peso (100). O nanismo dos ratinhos Ames foi acompanhado por um aumento da ingestão calórica por grama de peso corporal e do tempo de vida em mais de $50 \%$, comparativamente com os cohortes normais (151). Outro exemplo do desvio a esta explicação da "Teoria da Velocidade de Vida" avançada por Sacher (209), são as diferenças encontradas nas variações metabólicas dos morcegos que hibernam e dos que não hibernam. Apesar da grande redução metabólica durante a hibernação (cerca de 10 vezes menos dispêndio energético), os morcegos que não hibernam têm o mesmo tempo de vida (99). Em conjunto, estes resultados sugerem que não existe uma reserva energética ou número de batimentos cardíacos pré determinados geneticamente que determine ma longevidade do indivíduo. A influência metabólica na longevidade poderá ser, parcialmente, explicada pelo aumento da produção de espécies reactivas de oxigénio (ERO), nos animais metabolicamente mais activos. De facto, Ku et al. (121) constataram que, com algumas excepções, os animais com maior metabolismo basal são aqueles que produzem maior quantidade de ERO e cuja longevidade é menor. Estes resultados sugerem uma nova explicação para a variação da longevidade com o metabolismo basal, que poderá estar relacionada com mecanismos de stress oxidativo responsáveis pelo aumento da lesão interna das células e tecidos que resultam num aumento do desequilibro interno e, por fim, na morte $(89,197)$.

\section{Teoria do Envelhecimento Celular}

Os esforços para compreender o papel da célula no fenómeno de envelhecimento tiveram início em 1891, quando Weismann especulou sobre a existência de um potencial limitado da capacidade de duplicação das células somáticas nos animais superiores (para ref. ver 206). Contudo, só mais tarde Hayflick e Morhead (97) confirmaram experimentalmente esta suposição. Os estudos desenvolvidos por Hayflick deram um contributo valioso para a evolução das teorias gerontológicas, tendo como objecto de estudo o fenómeno de envelhecimento celular. Até então, os estudos desenvolvidos em células somáticas apontavam para a possibilidade deste fenómeno não ocorrer ao nível celular. Esta hipótese teve origem no célebre estudo realizado por Alexis Carrel (33) que colocou fibroblastos provenientes do coração de galinha em meio de cultura. Os fibroblastos duplicaram-se indefinidamente, tendo Carrel 
decidido terminar a cultura voluntariamente após 34 anos. Os resultados deste estudo foram confirmados numerosas vezes, em diversos tecidos animais e humanos, e levaram os biogerontologistas a considerar que as células, quando mantidas em meio de cultura, eram imortais e, por isso, não seria possível estudar o fenómeno de envelhecimento ao nível da célula. Este fenómeno resultaria, assim, da interacção fisiológica das células apenas quando estão organizadas em tecidos ou órgãos. No entanto, após terem alterado o meio de cultura, Hayflick e Morhead (97) constataram que os fibroblastos humanos normais têm uma capacidade finita de duplicação celular. Estes investigadores demonstraram que, quando células normais de embrião humano crescem em condições favoráveis, o fenótipo de envelhecimento e a morte são uma consequência inevitável após cerca de 50 duplicações da população. Desta forma, os autores demonstraram que a morte da cultura de células humanas normais não se deve a algumas causas triviais, que envolvem os componentes ou condições do meio de cultura, mas é antes uma consequência das características genéticas das próprias células. As diferenças entre os resultados obtidos anteriormente por Carrel (33) e os observados por Hayflick e Morhead (97), podem ser explicadas pelas características do meio de cultura utilizado e pelos cuidados na sua manutenção. Com efeito, Hayflick $(95,97,145)$ refere que nas experiências em que os fibroblastos evidenciaram um tempo de vida ilimitado, o meio de cultura estava contaminado por vírus ou compostos capazes de induzir mutações nas células em cultura, tornando-as cancerosas.

A aceitação destes resultados pela comunidade científica da época não foi pacífica, tendo sido atribuídos erros na confecção do meio de cultura e na possível contaminação por vírus (97). De acordo com a perspectiva vigente na época, o segredo do "elixir da juventude" poderia residir no meio em que as células vivem.

Posteriormente, Hayflick (95) identificou dois tipos de células in vivo que têm comportamentos diferentes in vitro. Estes dois tipos de células são (i) células normais, diploides e mortais e (ii) células cancerosas anormais, heteroploides e imortais. O comportamento destas células in vitro é diferente, tendo as primei- ras uma capacidade de duplicação finita, enquanto que nas segundas esta capacidade é infinita. Esta constatação foi um marco importante no estudo do fenómeno de envelhecimento celular.

Outro contributo valioso da investigação conduzida por Hayflick foi a descrição das propriedades das células diploides, que permitiu explicar a existência de um potencial de duplicação celular inferior nas células adultas, comparativamente às células embrionárias (145). Observações posteriores, realizadas num sistema de cultura de células in vitro, permitiram considerar a cultura senescente após a duplicação de 70 populações, quando a densidade celular de inoculação não duplicou, durante duas semanas de alimentação (171). A consistência dos resultados obtidos em culturas de células levou os investigadores a considerar que a longevidade é determinada geneticamente, uma vez que a célula tem uma capacidade de proliferação predefinida, isto é, o número de replicações é limitado $(106,107,143,241)$. A comprovação de que as células somáticas mitóticas que integram um organismo têm uma capacidade limitada de se duplicarem, que é programada geneticamente e que varia com a longevidade da espécie (145), impulsionou a investigação científica para a pesquisa dos genes responsáveis pelo fenómeno de envelhecimento, também conhecidos como "gerontogenes". Os estudos genéticos em humanos, relacionados com a longevidade, são normalmente desenvolvidos em gémeos (43). De acordo com estes autores, as reduzidas dimensões das amostras, assim como a semelhança do meio envolvente, tendem a limitar a utilidade dos resultados destes trabalhos. Num estudo com uma amostra considerável (600 pares de gémeos dinamarqueses monozigóticos e dizigóticos), nascidos no século XIX, foi encontrada uma influência da hereditariedade na longevidade de apenas 30\% (153). A existência de um único gene responsável pelo fenómeno de envelhecimento em humanos parece pouco provável, apesar de terem já sido identificados alguns genes relacionados com doenças específicas de idades avançadas. Certos alelos específicos do gene da apoplipoproteina E estão associados a um aumento do risco de desenvolvimento tardio da doença de Alzheimer (43). Há também variações nos alelos dos receptores da vitamina $\mathrm{D}$, em que alguns alelos estão associados a uma maior suscepti- 
bilidade para a osteoporose (167). Os polimorfismos genéticos do gene HLA (human leucocyte antigen) estão associados a muitas doenças hereditárias e parecem contribuir para acentuar os processos de envelhecimento secundário (162). Outro exemplo é a identificação do gene WRN (gene responsável pelo síndrome de Werner), localizado no cromossoma 8 , responsável pelo envelhecimento acelerado dos indivíduos com síndroma de Werner (149). Em humanos normais, a investigação dos gerontogenes tem permitido identificar genes responsáveis pelo desenvolvimento de doenças associadas à idade, mas não genes específicos do fenómeno de envelhecimento como acontece em organismos mais simples, como em nematóides e em leveduras.

\section{Teoria dos Telómeros}

A existência de um tempo de vida finito nas células eucariotas normais, e a capacidade das células cancerosas em superá-lo, pode depender dos telómeros (150). Estas estruturas, compreendem sequências de nucleótidos que protegem as extremidades dos cromossomas da sua degeneração e da fusão com outros cromossomas, prevenindo a instabilidade genómica $(22,34,105,123,150,170)$. Para além destas funções, os telómeros desempenham também um papel importante indirecto no controlo da proliferação das células normais e no crescimento anormal do cancro $(81,105,150)$. Na ausência da telomerase, uma enzima que adiciona repetições sucessivas de bases de DNA telomérico aos telómeros, em cada duplicação celular a célula perde entre 50 e 201 pares de bases (bp) de DNA telomérico $(105,170)$. Aparentemente, as células humanas deixam de se dividir quando o comprimento final do DNA telomérico atinge aproximadamente $4-7$ bp (15 a 20 nas células germinais) prevenindo, assim, a fusão com outros cromossomas (105). O encurtamento dos telómeros ocorre porque a maioria das células somáticas normais não sintetiza telomerase (123). No entanto, nas células cancerosas, a síntese de telomerase é activada, o que poderá contribuir para a capacidade destas células se dividirem continuamente (150). Esta enzima foi identificada pela primeira vez em meados da década de 80 , do século passado, por Greider e Blackburn $(74,75,76)$, em organismos simples como a Tetrahymena. A telomerase é uma ribonucleoproteina cujas subunidades de ácido ribonucleico (RNA) incluem sequências que complementam a guanina da repetição telomérica (123). O RNA serve como um template para a síntese de repetições teloméricas, e pode ainda desempenhar um papel chave na afinidade química da enzima (123, $150)$. De acordo com Blackburn $(21,22)$, as alterações no seu RNA alteram as propriedades enzimáticas da telomerase. De facto, uma determinada modificação no RNA da telomerase da Tetrahymena alterou tão intensamente a sua actividade que os telómeros encurtaram muito rapidamente, motivando a morte das células $(76,77)$. Deste modo, a Tetrahymena necessita da presença da telomerase para manter a sua imortalidade $(77,150)$.

Contudo, como Hayflick e Morhead (97) demonstraram, as linhas de células normais dos mamíferos não são imortais, o que poderá ser o resultado do encurtamento progressivo dos telómeros. Apesar de serem já conhecidos alguns factores que podem interromper a divisão celular e induzir posteriormente a morte quando o telómero fica muito pequeno, há ainda um longo caminho a percorrer para que se conheçam todos os mecanismos e factores que lhe estão associados. Sabe-se que à medida que as células se aproximam da fase de senescência replicativa começam a expressar a proteína p53, resultante de um gene supressor tumoral, que interrompe o ciclo celular nas fases G1 e S (150). Esta proteína é particularmente importante no controlo do ciclo celular, estando a sua inactivação ou mutação associada a um aumento da proliferação celular, independentemente do comprimento dos telómeros (105). Por outro lado, tem sido constatado um aumento da p53 nas células em fase de senescência replicativa e nas células em que o DNA foi lesado por ERO (105). Desta forma, a possibilidade de surgirem células com informação genética alterada é prevenida, mesmo que o comprimento dos telómeros permita a continuação da proliferação celular. Por outro lado, se os factores estocásticos induzirem mutações nesta proteína, inactivando-a, poderão sobrepor-se aos mecanismos genéticos de controlo do fenómeno de envelhecimento celular.

Estes dados indicam que o papel dos telómeros no fenómeno de envelhecimento celular poderá não ser tão decisivo como tem sido descrito. Os telómeros 
poderão ter um papel preponderante no envelhecimento tecidular onde as células mantêm a sua capacidade proliferativa ao longo da vida do indivíduo, embora nos tecidos compostos por células permanentemente pós-mitóticas, tais como os neurónios e os cardiomiócitos, a sua função seja mais restrita. $\mathrm{O}$ fenómeno de envelhecimento nestes tecidos deve-se, provavelmente, à acumulação de lesões celulares sucessivas induzidas por factores de natureza química ou mecânica, como por exemplo o aumento do stress oxidativo nas células nervosas $(12,140)$. A diminuição significativa do número de células funcionais, quer por morte celular ou por incapacidade de reparação dos danos, poderá determinar a funcionalidade dos respectivos órgãos, culminando com a morte do indivíduo. De facto, em órgãos constituídos, fundamentalmente, por células permanentemente pós-mitóticas a "Teoria dos Telómeros" não se aplica. O processo de envelhecimento destes órgãos parece depender muito mais da acção dos factores estocásticos, do que dos mecanismos de regulação genética. Neste sentido, o "relógio biológico" que determina a longevidade do indivíduo, parece não fazer sentido quando a análise deixa de ser a longevidade das linhas de células em cultura e se passa a considerar um indivíduo como um todo. A "Teoria dos Telómeros" é ainda posta em causa quando se tenta explicar as diferenças de longevidade entre as espécies animais com base no comprimento destas estruturas. Ou seja, seria de esperar que o maior comprimento dos telómeros das células mitóticas estivesse associado a uma maior longevidade da linha celular, o que não acontece (217). De facto, os telómeros dos fibroblastos humanos têm um menor comprimento do que os fibroblastos de ratinhos e, no entanto, dividem-se muitas mais vezes antes de atingir a senescência replicativa. $A$ actividade da telomerase é também maior nos fibroblastos de ratinhos do que nos fibroblastos de humanos (207), pelo que o encurtamento dos telómeros seria ainda mais acentuado nestes últimos. No entanto, nos fibroblastos humanos, o número de pares de bases de DNA telomérico que a célula perde em cada duplicação celular poderá ser inferior ao dos fibroblastos de ratinhos, a par de uma capacidade de reparação do DNA mais eficiente nos primeiros (207). Em conjunto, estas evidências suge- rem que o comprimento dos telómeros, por si só, não se relaciona com a longevidade das diferentes espécies animais. Contudo, apesar do comprimento dos telómeros e da longevidade das diferentes espécies animais não estarem correlacionados, Rohme (205) constatou a existência de uma correlação entre a longevidade das células em cultura e a longevidade das respectivas espécies animais. Este facto, sugere a existência de outros mecanismos responsáveis pelo fenómeno de envelhecimento celular, mais decisivos para a longevidade do que o comprimento inicial dos telómeros. Com efeito, a lesão oxidativa do DNA tem, possivelmente, um efeito mais decisivo na longevidade das células do que o comprimento dos telómeros $(58,73,140,280)$. Independentemente do comprimento dos telómeros, a lesão oxidativa do DNA pode desencadear mecanismos de reparação celular que, caso não sejam eficazes, podem resultar na morte celular $(58,280)$.

Em conjunto, as evidências apontam para um papel moderado dos telómeros no fenómeno de envelhecimento, que deverá ser mais decisivo nos tecidos constituídos por células mitóticas e naqueles onde a capacidade regenerativa é determinante, tendo, no entanto, um papel muito modesto nos órgãos principalmente constituídos por células pós-mitóticas $(77,204)$. É possível que o progressivo encurtamento dos telómeros constitua apenas um dos fenótipos do envelhecimento biológico e não seja a causa do processo.

Outras teorias genéticas, que tiveram uma influência determinante no desenvolvimento da investigação gerontológica, centraram a sua investigação nas alterações funcionais, observadas com a idade, nas proteínas, na regulação neuro-endócrina e na resposta imunológica.

\section{Teoria da Mutagénese Intrínseca}

A "Teoria da Mutagénese Intrínseca" de Burnet (31) considera que a longevidade das diferentes espécies animais difere devido a uma constituição genética específica, que regula a fidelidade do seu material genético e sua replicação $(39,148)$. De acordo com esta teoria, a longevidade do animal depende do menor número de erros na replicação do seu DNA celular e da capacidade das respectivas enzimas reparadoras do DNA. Deste modo, o maior ou menor tempo de vida das diferentes espécies animais esta- 
ria associado a uma maior ou menor acumulação de mutações nas respectivas células somáticas (148). Quando a acumulação de mutações nas células somáticas impossibilitasse a manutenção da fidelidade e replicação do material genético, a célula começaria a evidenciar um fenótipo de envelhecimento, de perda de funcionalidade. No entanto, os processos de manutenção da fidelidade da replicação do DNA são bastante eficazes, impedindo a acumulação de mutações por replicação do DNA danificado (114). De facto, a enzima DNA polimerase cataliza a inserção correcta dos pares de bases a uma velocidade de 300-500 bases por segundo $(185,279)$. De acordo com estes autores, em média, ocorre apenas um erro em cada $10^{5}$ ou em $10^{6}$ bases inseridas e, quando a polimerase comete um erro, interrompe a reacção para remover, praticamente, todos os erros. No entanto, estima-se que em cada $10^{3}$ a $10^{4}$ bases reparadas uma base modificada escape a esta reparação, de tal forma que a frequência de erro varia entre um em $10^{8}$ a $10^{10}$ pares de bases (53). Estes erros poderão ainda ser reparados pelos sistemas de reparação do DNA (114). Curiosamente, o aumento das mutações do DNA poderá inibir a velocidade das reacções da DNA polimerase e, deste modo, reduzir a possibilidade de sintetizar proteínas modificadas (279). Assim, os mecanismos responsáveis pela manutenção da fidelidade do material genético apenas permitem que ocorra um número reduzidíssimo de erros na síntese de proteínas. A maioria das proteínas danificadas detectadas nas células envelhecidas resulta, essencialmente, de modificações motivadas por reacções de oxidação e de glicosilação (61). A “Teoria da Mutagénese Intrínseca” parece não explicar o fenómeno de envelhecimento uma vez que há poucas evidências experimentais que sustentem esta hipótese.

\section{Teoria Neuro-endócrina}

Uma das teorias genéticas do fenómeno de envelhecimento mais relevantes é a “Teoria Neuro-endócrina” $(60,61)$ e constitui uma hipótese alternativa para explicar a degeneração funcional associada à idade. De acordo com esta teoria, o nível de envelhecimento é o resultado do declínio de diversas hormonas do eixo hipotálamo-pituitária-adrenal que controlam o sistema reprodutor, o metabolismo e outros aspectos do funcionamento normal de um organismo $(39,61,137,160,234)$. O sistema neuro-endócrino, controlado pelo hipotálamo e pela glândula pituitária, regula a libertação e inibição das hormonas secretadas para a circulação sanguínea sob a influência dos neurotransmissores e neuropeptideos $(211,249)$. Esta teoria defende que a actividade do hipotálamo depende da expressão de genes específicos, os quais, independentemente da influência dos factores estocásticos, alteram a sua expressão com a idade, condicionando um conjunto de funções directamente dependentes do sistema neuro-endócrino (115). A incapacidade funcional do sistema reprodutor feminino (menopausa) e suas características (diminuição da secreção hormonal do ovário, aumento das gonadotrofinas) $(276,278)$ constituem fenótipos de envelhecimento. Por exemplo, os estrogénios não afectam apenas a capacidade reprodutora feminina, mas atingem também uma série de outras funções como a continência urinária, a absorção de nutrientes, o metabolismo ósseo e mineral, a pressão sanguínea e a função cardiovascular, a memória e cognição, organização e expressão dos ritmos diários e a progressão das doenças degenerativas relacionadas com a idade (276). Assim, a "Teoria Neuro-endócrina" considera que a incapacidade fisiológica do organismo associada à idade pode ser explicada com base na alteração hormonal resultante da modificação da expressão genética. As hormonas têm um importante papel trófico e integrativo na manutenção da função dos tecidos, pelo que a sua deficiência tem como resultado a deterioração da função tecidular (234). A constatação de que a alteração hormonal associada à idade e o fenótipo de envelhecimento são idênticos entre os indivíduos da mesma espécie, reforça a importância da influência genética na regulação neuro-endócrina.

A utilização de modelos animais sujeitos a uma mutação num gene específico, veio permitir estudar o efeito de uma hormona específica no processo de envelhecimento. No entanto, os resultados nem sempre são consistentes com os observados num meio onde os factores estocásticos não são controlados. Por exemplo, nos humanos, os níveis da hormona de crescimento diminuem significativamente com a idade, estando esta diminuição associada a um aumento da adiposidade, dos lípidos no sangue e da perda de 
massa magra (92). Em conjunto, estas alterações podem contribuir para o desenvolvimento de doenças cardiovasculares e de outros factores que influenciam os processos de envelhecimento secundário associados a uma mortalidade precoce. Consequentemente, é frequente o recurso a terapias com hormona de crescimento, retardando os efeitos negativos associados à sua redução $(20,92)$. Neste sentido, estas alterações hormonais associadas à idade são consistentes com o importante papel da regulação endócrina no fenómeno de envelhecimento.

No entanto, nos ratinhos, a ausência prolongada da hormona de crescimento parece exercer efeitos anti-envelhecimento $(13,27,92)$. De facto, os ratinhos Ames anões que sofreram uma mutação localizada no cromossoma 11, traduzida por uma deficiência na hormona de crescimento, na prolactina e na hormona estimuladora da tiroide, aumentaram a sua longevidade em $50 \%$, nos machos, e $61 \%$, nas fêmeas, comparativamente com os ratinhos normais (27). Em adultos, o tamanho dos ratinhos que sofreram esta mutação era aproximadamente três vezes menor do que os normais. Os níveis plasmáticos do factor de crescimento tipo insulínico-I (IGF-I) e tiroxina eram extremamente baixos e a maturação sexual foi retardada (13). De acordo com estes autores, os efeitos desta mutação na longevidade devem-se a um atraso no processo de maturação, após o qual a taxa de mortalidade nos dois grupos é idêntica. Apesar desta aparente vantagem para longevidade dos animais mutantes, a deficiência de prolactina tornou as fêmeas inférteis, pondo em causa a manutenção da espécie.

Outras mutações realizadas em ratinhos que produziram um fenótipo de nanismo semelhante ao dos ratinhos Ames (ratinhos Snell anões - deficiência da hormona de crescimento, da prolactina e da hormona tireo-estimulante; ratinhos "little" - deficiência da hormona de crescimento; e ratinhos com mutação no gene que codifica a síntese das proteínas sensíveis à presença de hormona de crescimento) associadas à ausência da hormona de crescimento ou da sensibilidade à sua presença, induziram um aumento da longevidade $(13,92)$. Também nestes casos, o aumento da longevidade deveu-se, fundamentalmente, a um atraso da manifestação do fenótipo de envelhecimento, uma vez que, após atingirem a matura- ção, a taxa de mortalidade foi idêntica à dos ratinhos normais. Paralelamente, os ratinhos Snell anões e os ratinhos little evidenciaram esterilidade generalizada nos machos e nas fêmeas, e nos ratinhos com redução da sensibilidade à hormona de crescimento a fertilidade nas fêmeas reduziu-se significativamente. Mais uma vez, os resultados sugerem que a análise das implicações genéticas do controlo neuro-endócrino na longevidade deverá ter em conta as repercursões na manutenção da espécie. De facto, um dos principais problemas das teorias biológicas do envelhecimento é a explicação das diferenças de longevidade das várias espécies animais. Portanto, os estudos com mutantes permitem aumentar o conhecimento sobre mecanismos biológicos específicos, mas não deverão preterir os resultados obtidos com populações normais. Com efeito, vários mecanismos, influenciados pela ausência da hormona de crescimento, poderão ter aumentado a longevidade nos ratinhos mutantes estudados. O metabolismo basal nos mutantes é menor do que nos ratinhos normais, provavelmente devido à ausência dos efeitos anabólicos e térmicos da hormona de crescimento. Mesmo nos ratinhos Ames anões, onde a ingestão calórica por grama de peso corporal foi maior do que a dos ratinhos normais, o metabolismo basal foi menor (151). No entanto, é possível que a absorção dos nutrientes tenha sido menor devido à ausência dos efeitos estimuladores da hormona de crescimento e do IGF-I no tracto gastrointestinal (179). Estes resultados evidenciam as implicações da regulação neuro-endócrina no metabolismo, acentuado ou não o processo de envelhecimento. Não obstante o carácter genético desta teoria, as alterações metabólicas decorrente das alterações neuro-endócrinas no metabolismo poderão desencadear outros factores, de natureza estocástica, capazes de exarcebar a degeneração do sistema neuro-endócrino. Por exemplo, tem sido descrito um aumento das lesões oxidativas, nomeadamente ao nível do hipotálamo, que poderão interferir com os mecanismos de sinalização do sistema neuro-endócrino com consequências ao nível do fenómeno de envelhecimento do organismo (109). De facto, Jiang et al. (109) constataram que o fenómeno de envelhecimento está associado a uma alteração na expressão de 99 genes do hipotálamo em ratinhos, que se traduziu num aumento da acti- 
vidade das enzimas da cadeia de transporte de electrões mitocondrial. O aumento da actividade destas enzimas poderá ser responsável por um aumento da produção de ERO no hipotálamo dos ratinhos. Ao alterar a regulação hipotalâmica dos processos fisiológicos através do sistema neuro-endócrino, o aumento da produção de ERO no hipotálamo pode acentuar o processo de envelhecimento.

Considerando esta perspectiva, as alterações neuro-endócrinas podem até nem ser a causa, mas sim uma manifestação do processo de envelhecimento primário que, pelas modificações hormonais que induzem, aceleram esse processo.

Apesar da etiologia das alterações neuro-endócrinas com a idade ser desconhecida, tem sido proposto que as alterações celulares e moleculares em sub-populações específicas de neurónios no hipotálamo e pituitária e/ou estruturas de suporte no cérebro, contribuem para a diminuição da função cerebral (156). A causa de perturbações específicas pode estar relacionada com a perda de neurónios, erro genético, ou produção de ERO, que leva a aberrações progressivas na função dos tecidos e que acentua o fenómeno de envelhecimento e a progressão das doenças (234). Deste modo, as alterações neuro-endócrinas constituem mediadores do fenómeno de envelhecimento iniciado por alterações celulares em sub-populações específicas de neurónios ou sistemas que interagem com proximidade com os neurónios hipotalâmicos (234). Diversos factores estocásticos poderão influenciar a velocidade de perda de funcionalidade dos neurónios hipotalâmicos, entre os quais o aumento da produção de ERO parece ter um papel importante.

\section{Teoria Imunológica}

Por último, a "Teoria Imunológica" (268) aborda as alterações nas respostas imunológicas associadas à idade. Os humanos e roedores idosos evidenciam declínios em vários aspectos da protecção imunológica, incluindo a formação de auto-anticorpos com elevada afinidade, diminuição da resposta das células $\mathrm{T}$ aos mitogéneos e menor resistência à infecção e à doença $(39,56,161,162)$. Paralelamente, a produção de interleucina-2 (IL-2) e do ácido ribonucleico mensageiro da IL-2 (RNAm IL-2) diminui com a idade, em células $\mathrm{T}$ de humanos e roedores (62).
Num estudo descrito por Miller $(161,162)$, a combinação de alguns índices imunológicos, incluindo uma elevada proliferação das células T, um elevado número de células $\mathrm{B}$, e uma ratio de células CD8/CD4 relativamente baixa, permitiu prever uma sobrevivência de aproximadamente mais dois anos em indivíduos com idade compreendida entre $86 \mathrm{e}$ 92 anos. Por outro lado, o fenómeno de envelhecimento está associado a alterações na capacidade de resposta imunológica, particularmente nas funções associadas ao sistema $\mathrm{H}-2$, no rato, e HLA, nos humanos. Estas alterações podem representar um processo patológico inicial que contribui para a acumulação de lesões celulares, acentuando os processos de envelhecimento secundário $(224,269)$. Alguns autores referem que a acumulação de células $\mathrm{T}$ de memória está relacionada com uma fraca capacidade da resposta proliferativa das células $\mathrm{T}$ (161, 162) e de alterações na composição das células $T$ $(56,162,178)$. Ao longo do fenómeno de envelhecimento tem sido constatada uma alteração na composição dos subgrupos das células CD4 que parece estar associada à diminuição progressiva da capacidade de resposta proliferativa e à diminuição da produção de IL-2 (178). De acordo com estes autores, a acumulação das células $\mathrm{T}$ de memória poderá ser o resultado da perda da regulação do ciclo celular, devido à incapacidade de expressar a proteína p53, e/ou à ocorrência de mutações no gene que a codifica. Nestas situações, a célula será impedida de cometer suicídio em situações de desequilíbrio interno, como acontece quando ocorre um aumento do stress oxidativo e ocorre a acumulação de células alteradas com a idade $(23,178)$. Neste sentido, a alteração da resposta imunológica com o processo de envelhecimento poderá ser o resultado da acção de inúmeros factores estocásticos que interferem com os mecanismos de controlo de resposta aos mitogéneos. A diminuição da capacidade de defesa do organismo poderá ser uma consequência do fenómeno de envelhecimento e não uma causa do mesmo, como sugere a "Teoria Imunológica".

A divisão estanque das teorias biológicas do envelhecimento surge da necessidade de estudar, isoladamente, as causas do fenómeno. No entanto, a inter-relação entre os processos biológicos do organismo é tão próxima que esta separação das teorias pode 
tornar-se absurda. Considerando apenas as teorias genéticas, o papel dos telómeros poderá explicar, por exemplo, o envelhecimento do sistema reprodutor, que, por sua vez, interfere com o sistema neuro-endócrino, com processos anabólicos e catabólicos e, ainda, com a eficiência do sistema de defesa do organismo $(22,77,187)$. Por outro lado, os mecanismos que controlam o ciclo celular poderão ser alterados mediante a acção dos factores estocásticos (66, 88), sobrepondo-se aos factores de regulação genética do fenómeno de envelhecimento.

\section{TEORIAS ESTOCÁSTICAS}

As Teorias Estocásticas sugerem que a perda de funcionalidade que acompanha o fenómeno de envelhecimento é causada pela acumulação aleatória de lesões, associadas à acção ambiental, em moléculas vitais, que provocam um declínio fisiológico progressivo (39). Várias teorias estão incluídas neste grupo, entre as quais se destacam a Teoria das Mutações Somáticas, a Teoria do Erro-catástrofe, a Teoria da Reparação do DNA, a Teoria da Quebra de Ligações, a Teoria da Glicosilação Avançada e a Teoria do Stress Oxidativo.

Diversas teorias estocásticas do envelhecimento fundamentaram o seu conhecimento em experiências com radiações ionizantes. Entre estas, uma das teorias que assumiu maior protagonismo foi a proposta por Szilard (244), em que os genes das células somáticas são inactivados por lesões aleatórias, cuja acumulação com a idade leva à disfunção e morte das células. Inicialmente, a influência destas lesões na perda de funcionalidade e morte celular é mascarada pelos mecanismos de reparação e regeneração; contudo, à medida que estes perdem eficácia, as lesões vão-se acumulando, provocando desequilíbrios internos que culminam na morte do organismo. As radiações provocam mutações genéticas que se acumulam e aceleram o fenómeno de envelhecimento, de tal modo que condicionam a morte celular (244).

\section{Teoria das Mutações Somáticas}

A “Teoria das Mutações Somáticas" foi uma das primeiras tentativas de compreensão do fenómeno de envelhecimento ao nível molecular. Esta teoria surgiu da constatação que doses de radiações sub-letais são frequentemente acompanhadas por uma dimi- nuição do tempo de vida (41). A atrofia, a modificação da cor dos pêlos e a diminuição do tempo de vida de ratos submetidos a radiações parecia suportar esta teoria (42). No entanto, a análise matemática das curvas de sobrevivência dos ratos expostos à radiação ionizante exprime um aumento da taxa de mortalidade inicial, período em que as radiações ionizantes tiveram maior efeito, não se tendo verificado um aumento na taxa de mortalidade com a idade (209). A mortalidade precoce evidenciada pelos ratos submetidos a radiações ionizantes não terá sido provocada por processos de envelhecimento primário, mas sim pelo desenvolvimento de patologias neoplásicas que provocaram a morte dos animais (61).

Os efeitos das radiações ionizantes no encurtamento do tempo de vida orientaram a investigação para o estudo das alterações no DNA relacionadas com a idade. Os dados provêm de estudos que avaliaram a ocorrência de mutações espontâneas determinadas indirectamente pela substituição de amino-ácidos, erros na síntese de DNA e resistência às purinas citotóxicas $(61,160)$.

As radiações ionizantes têm sido utilizadas como um mecanismo indutor de desequilíbrios homeostáticos que activam os mecanismos de defesa e de reparação, tal como poderia ser utilizado o paraquat, o tabaco ou outro agente citotóxico $(61,68,160,262$, $266,267)$. As radiações ionizantes induzem a quebra de ligações ou dimerização das pirimidinas adjacentes do DNA, causando mutações que repercutem na síntese e funcionalidade das proteínas.

Os efeitos das radiações e a forma como o organismo reage à sua agressão são objecto de estudo de outras teorias, tais como a "Teoria da Reparação do DNA" e a "Teoria do Stress Oxidativo". Neste sentido, parte da investigação que utiliza as radiações ionizantes como agente stressor tem estado associada ao estudo do cancro da pele, mediante a alteração de proteínas específicas que controlam o ciclo celular, tal como a p53, e à diminuição da capacidade de reparação das lesões do DNA ao longo do fenómeno de envelhecimento (73). O aumento das lesões oxidativas do DNA nas células expostas a radiações ionizantes (274) tem também sido utilizado para explicar a influência do stress oxidativo no fenómeno de envelhecimento, um dos mecanismos que 
maior aceitação tem vindo a adquirir pela comunidade científica para a compreensão deste fenómeno.

\section{Teoria do Erro-catástrofe}

A "Teoria do Erro-catástrofe" do envelhecimento celular, proposta por Orgel (180), postula que os erros na síntese de uma proteína podem ser utilizados na síntese de outras proteínas, levando a uma diminuição progressiva da fidelidade e à eventual acumulação de proporções de proteínas aberrantes, potencialmente letais. Estes erros assumem significado especial quando afectam proteínas envolvidas na síntese de DNA, resultando na perda de fidelidade do DNA replicado, aumentando, consequentemente, as mutações somáticas e originando, eventualmente, patologias e disfunção celular (148). Para testar esta teoria, Harley et al. (87) determinaram a frequência dos erros na síntese proteica em várias culturas de fibroblastos de dadores humanos, jovens e idosos. Como corolário desta teoria deveria verificar-se uma menor velocidade da ocorrência de erros traducionais nos fibroblastos transformados em linhas permanentes (imortais) do que nas células envelhecidas. No entanto, contrariamente ao esperado, Harley et al., (87) constataram uma maior velocidade de erros na síntese proteica nas células imortais do que nas envelhecidas. Estas células (provenientes de dadores jovens, de idosos, de indivíduos com Progeria ou com síndrome de Werner), possuíam proteínas idênticas às observadas nas fases mais jovens das células em cultura. Os resultados deste estudo apontam para uma baixa influência da ocorrência de erros na tradução das proteínas no fenómeno de envelhecimento.

Para testar a "Teoria do Erro-catástrofe", Edelmann e Gallant (55) promoveram a não incorporação de cisteína na flagelina. Quando o crescimento da Escherichia coli ocorria na presença de estreptomicina (aumenta os erros de translação), a taxa de mal-incorporação de cisteína na flagelina aumentava até cerca de 20 vezes, após seis gerações. No novo estado de equilíbrio, não havia perda de viabilidade celular, apesar do crescimento ser mais lento. Depois de remover a estreptomicina, a frequência do erro voltou rapidamente ao nível inicial. Este estudo demonstra que o aumento substancial de erros não é incompatível com a continuação da proliferação celu- lar da bactéria, em condições em que parece pouco provável que a selecção por resistência ocorra. Este estudo demonstra, ainda, que aumentos significativos de erros não têm de precipitar erros-catástrofe (61). De facto, as proteínas alteradas, presentes nas células envelhecidas, não são consequência da diminuição da fidelidade na síntese proteica, mas sim de modificações pós-traducionais de processos como a oxidação e glicosilação $(61,83,237)$. A capacidade de remover estas proteínas alteradas está comprometida nas células envelhecidas, contribuindo, assim, para a sua progressiva acumulação (83).

\section{Teoria da Reparação do DNA}

Hart e Setlow (90) desenvolveram a "Teoria da Reparação do DNA". De acordo com estes autores, é a velocidade de reparação do DNA que determina o tempo de vida de indivíduos de espécies diferentes e entre indivíduos da mesma espécie. Estas conclusões foram retiradas com base na constatação de diferentes velocidades de reparação de fibroblastos em cultura, expostos à luz ultravioleta, de dadores de sete espécies de mamíferos. No entanto, estes resultados não foram confirmados em estudos posteriores realizados com outras espécies de mamíferos (281). Para testar as diferenças entre indivíduos da mesma espécie, os investigadores colocaram a hipótese da capacidade e da eficiência de reparação, nas células em cultura próximas do seu tempo de vida limite, serem consideravelmente menores do que nos primeiros dias em cultura. Diversos estudos constataram uma perda progressiva da capacidade de reparação do DNA lesado pelas radiações ionizantes, com a idade $(73,104,127)$, acompanhada por uma diminuição da velocidade de remoção dos produtos da lesão do DNA e dos níveis de proteína p53 com a idade (73). Estes autores sugerem que o fenómeno de envelhecimento é acompanhado por uma diminuição da sensibilidade da proteína p53 ao DNA lesado, aumentando a susceptibilidade das células desenvolverem fenótipos cancerosos. Vários factores podem estar na origem da acumulação de lesões do DNA. De facto, o aumento do peróxido de hidrogénio originou uma acumulação de produtos da lesão oxidativa do DNA, que inibiram a reparação do mesmo pelo $\mathrm{N}$-acetoxi2-acetilaminofluoreno, um indutor da reparação do DNA, em leucócitos humanos (189). Este estudo 
demonstra que o stress oxidativo pode ser um dos mecanismos responsáveis pelo aumento da acumulação de moléculas de DNA danificadas com a idade, não só porque interage directamente com as mesmas, como também porque inibe os mecanismos de reparação das lesões.

A maioria dos estudos que testaram a alteração da capacidade de reparação do DNA ao longo do envelhecimento utilizou células mitóticas em cultura. Neste tipo de células, a capacidade de reparação do DNA diminuiu com a proximidade do término da cultura $(73,104,127,189)$. No entanto, nas culturas de células diferenciadas, provenientes de tecido nervoso e muscular, a capacidade de reparação do DNA lesado pelas radiações ionizantes foi pouco alterada com a proximidade do fim da cultura (86). Estes resultados revelam que a capacidade de reparação não é igual em todas as células e tecidos do mesmo organismo, pelo que a explicação do fenómeno de envelhecimento com base nestes mecanismos deverá ser considerada com algumas reservas. Ou seja, é provável que a diminuição da capacidade de reparação do DNA com a idade seja uma consequência do fenómeno de envelhecimento e não uma causa do mesmo, uma vez que a sua importância se resume apenas a um determinado tipo de células.

\section{Teoria da Quebra de Ligações}

O pressuposto de que a acumulação de proteínas modificadas pode levar à incapacidade funcional da célula normal foi defendida pela "Teoria da Quebra de Ligações" (39). Esta teoria teve origem na constatação de um aumento da quebra de ligações em macromoléculas como o DNA, o colagéneo e a elastina, com a idade, associado ao declínio dos processos fisiológicos. A quebra de ligações das proteínas pela glicosilação pode ser uma das causas do fenómeno de envelhecimento celular (131).

\section{Teoria da Glicosilação}

As reacções de glicosilação na modificação de proteínas são, actualmente, consideradas como um dos principais mecanismos responsáveis pelo fenómeno de envelhecimento celular. A "Teoria da Glicosilação" sugere que a modificação de proteínas pela glicose e a associação de reaç̧ões de Maillard (264) levam à formação de ligações cruzadas gra- duais no colagéneo que são características nos indivíduos idosos $(35,166)$. Esta teoria postula que as ligações cruzadas, causadas pelo elevado nível de glicémia e de glicose tecidular, conduzem à deterioração estrutural e funcional dos tecidos (98).

As reacções de glicosilação de proteínas têm recebido uma atenção particular na gerontologia molecular. Têm sido colocadas várias propostas teóricas relacionadas com o papel dos produtos glicosilados e seus derivados nos processos patofisiológicos associados ao envelhecimento secundário $(9,36,125,264)$. A adição não enzimática de açúcares a grupos de amino-ácidos livres, ocorre quer in vitro, quer in vivo com uma velocidade de reacção que depende do tipo de açúcar (264). Dos monossacáridos em circulação, a D-glicose é a que menos reage espontaneamente, enquanto que a D-galactose, comparativamente, reage 5 vezes mais rápido (29). Esta reacção, designada reacção de Maillard, resulta da ligação covalente entre um grupo aldeído livre do açúcar com um grupo amina livre, da proteína. Para além dos grupos amina das proteínas, também os grupos amina das bases de DNA são alvos potenciais de glicosilação (264). Geralmente as aldoses reagem mais rapidamente com os grupos amina livres das proteínas do que as cetoses (29). O produto da glicosilação passa, então, por um re-arranjo para uma cetoamina pouco estável conhecida como produto Amadori (264). Com o aumento da idade, é comum surgirem perturbações na regulação da homeostasia da glicose em humanos. Enquanto que em jejum a glicose sanguínea aumenta ligeiramente com a idade, após uma refeição, ou após a ingestão de glicose, o seu aumento é mais acentuado (71). Estas alterações vão-se acentuando com a idade e resultam, aparentemente, de uma diminuição da sensibilidade dos tecidos à insulina (38). Os efeitos da idade na capacidade secretora de insulina, para uma grande quantidade de glicose sanguínea, são controversos, mas a maioria dos autores é unânime em afirmar que a capacidade máxima das células $\beta$ do pâncreas em secretar insulina, quando estimulada suficientemente, não é alterada de forma significativa (61). Os níveis de insulina circulante são normais ou ainda ligeiramente superiores com o avançar da idade $(14,38)$. No entanto, devido à menor sensibilidade dos tecidos àquela hormona, o aumento dos seus níveis circu- 
lantes não é suficiente para estimular a captação adequada de glicose pelos tecidos. Os níveis de glicose sanguínea aumentam e a possibilidade de ocorrerem reacções de glicosilação é maior. De facto, a exposição in vivo da hemoglobina àquele açúcar no sangue resulta num aumento progressivo da formação de hemoglobina glicosilada $\left(\mathrm{HbA}_{1 c}\right)$, durante os 3 meses de vida dos eritrócitos em circulação (30). Em condições fisiológicas, a estabilidade dos níveis de glicosilação de algumas proteínas pode ser explicada pela remoção das mesmas, tal como acontece com a $\mathrm{HbA}_{1 c}$ (169). No entanto, a exposição prolongada a níveis elevados de glicose sanguínea, como por exemplo na diabetes, pode induzir um aumento da quantidade de $\mathrm{HbA}_{1 \mathrm{c}}$ até $30 \%$ da hemoglobina (61). Para além da glicose, o aumento da frutose nos diabéticos pode também ser um reagente para a formação de proteínas frutosiladas (51). No entanto, mesmo os diabéticos têm menos de $1-2 \%$ das lisinas glicosiladas no colagéneo.

Os produtos finais da glicosilação são colectivamente designados AGE (advanced glycation endproducts) (131), ou produtos Maillard avançados. Os tecidos podem ter neutralizadores dos AGE que surgem, particularmente, dos grupos amina livre como os compostos guanidina (174) e os amino-acidos como a taurina (165). Mesmo na presença de elevadas concentrações de glicose, a aminoguanidina bloqueia a formação de produtos de membrana fluorescentes nos ratos com indução de diabetes (174). As reacções in vitro também implicam a importância potencial de iões metálicos multivalentes e do estado redox local na oxidação de proteínas glicosiladas (165). A diminuição do estado redox da glutationa com a idade (em humanos, roedores e mosquitos) e no conteúdo sulfidrilo do cristalino de roedores (122) pode favorecer a formação dos AGE. Entre os AGE já identificados que aumentam com o processo de envelhecimento encontra-se a Pentosidina, um resíduo de amino-acidos de arginina e lisina quebrados por uma pentose. Nos indivíduos adultos saudáveis, não diabéticos, a pentosidina aumenta ao longo da vida, cerca de 6 vezes, na pele e na dura mater (165). Porém, as consequências deste aumento ainda não são conhecidas (61).

As possíveis disfunções causadas pelos AGE incluem: (i) aumento da pressão arterial devido à aterogenese, hipoteticamente por glicosilação das lipoproteinas de baixa densidade (LDL); (ii) perda da acomodação ocular; (iii) incapacidade funcional das "células T de memória" e, (iv) inactivação da $\mathrm{Cu}, \mathrm{Zn}-\mathrm{SOD}$, nos eritrócitos, diminuindo a capacidade antioxidante no sangue $(5,264)$.

Nesta teoria, a controvérsia reside em saber até que ponto as proteínas com período de vida longo podem evidenciar um aumento progressivo da glicosilação relacionada com a idade, tal como tem sido observado no colagéneo da pele humana, nas membranas basais e na osteocalcina (61). No entanto, na ausência de diabetes, nem todas as proteínas com longo período de vida revelam um aumento progressivo da glicosilação em função da idade. O cristalino de humanos normais, evidencia um aumento perceptível da glicosilação que é inferior a $10 \%$ entre os 10 e os 83 anos (186).

Diversos estudos com restrição calórica atribuem um significado específico aos AGE nas doenças relacionadas com a idade $(61,233,275)$. A restrição calórica retarda muitas alterações associadas à idade $\mathrm{e}$ também diminui a $\mathrm{HbA}_{1 c}$, devido a uma redução dos níveis de glicose sanguínea. Com algumas excepções (morcegos e aves), os níveis de glicose sanguínea estão inversamente correlacionados com os estados metabólicos, dimensões corporais e longevidade (258). Normalmente, os animais com menores dimensões corporais têm uma taxa metabólica superior e uma menor longevidade, comparativamente aos animais com maiores dimensões. No entanto, o metabolismo basal está também relacionado com a produção de ERO, podendo ser esta a explicação das diferenças descritas na longevidade de indivíduos de espécies diferentes e da mesma espécie.

De facto, em todos os mecanismos enunciados nas diversas teorias como possíveis causas do processo de envelhecimento, foi referida uma participação hipotética do stress oxidativo.

\section{Teoria do Stress Oxidativo}

O envolvimento dos radicais livres (RL) no fenómeno de envelhecimento e na doença foi proposto pela primeira vez por Harman em 1966 (88). Este autor considera que o fenómeno de envelhecimento é o resultado da acumulação de lesões moleculares provocadas pelas reacções dos RL nos componentes 
celulares ao longo da vida, que conduzem à perda de funcionalidade e à doença com o aumento da idade, conduzindo à morte.

Os RL constituem um grupo de substâncias químicas que contêm um ou mais electrões desemparelhados numa orbital, o que lhes confere uma grande instabilidade química $(17,82,83)$. Os RL existem em abundância na natureza, porém, aqueles que devido à sua elevada toxicidade biológica adquiriram maior importância são os radicais livres de oxigénio, tais como o superóxido $\left(\mathrm{O}_{2}{ }^{\bullet}\right)$, o hidroxilo $\left(\mathrm{HO}^{\bullet}\right)$ e o oxigénio singleto $\left(1 / 2 \mathrm{O}_{2}\right)(16,17,82,83,197)$. No entanto, foram sendo progressivamente identificadas outras moléculas derivadas dos RL de oxigénio, também reactivas e tóxicas para o organismo, que, por não conterem electrões desemparelhados, não podem ser designadas de RL. São exemplos destes compostos o peróxido de hidrogénio $\left(\mathrm{H}_{2} \mathrm{O}_{2}\right)$ e o ácido hipocloroso $(\mathrm{HOCl})(16,82,197)$. Existem, ainda, outros compostos altamente reactivos como as espécies reactivas de nitrogénio que têm também um papel importante na génese das lesões celulares e teciduais $(46,54,135,136,191)$. A característica comum a todas estas espécies é a potencialidade para reagir com outros compostos gerando RL (16, $82,83,197)$. Tendo em conta esta característica, são frequentemente designadas de espécies reactivas de oxigénio (ERO), incluindo na mesma categoria os radicais livres de oxigénio e outras moléculas altamente reactivas, sem electrões desemparelhados, mas que são potencialmente geradoras de RL (16, 82, 83). A identificação destas e de outras espécies reactivas e o reconhecimento dos processos antioxidantes e sistemas de reparação conduziram a reformulações na "Teoria dos Radicais Livres" com o aparecimento do conceito de stress oxidativo (284). Por definição, stress oxidativo consiste num desequilíbrio entre oxidantes e antioxidantes a favor dos primeiros $(64,219,220)$. A reacção de um RL com outra molécula produz um RL diferente, que pode ser mais ou menos reactiva do que a espécie original. Este processo tende a repetir-se continuamente terminando, apenas, quando a extremidade radical que contém o electrão desemparelhado formar uma ligação covalente com o electrão desemparelhado de outro radical (37). Assim, se os radicais primários produzidos não forem desactivados imediatamente por enzimas ou moléculas antioxidantes, provocam danos nas macromoléculas biológicas. A acumulação destas moléculas com a idade nas células e tecidos, resultante de um aumento da produção de ERO, ou de uma diminuição da capacidade antioxidante e/ou da velocidade de remoção e reparação das mesmas $(2,18,46,225,228,229,237)$, constitui um dos fenótipos de envelhecimento que terá originado a "Teoria do Stress Oxidativo".

Considerando a produção celular de ERO, e apesar destes compostos também serem produzidos noutros organelos (retículo endoplasmático, lisossomas, membranas, peroxissomas, citosol), a mitocôndria parece constituir a sua principal fonte $(3,18,46$, 130, 216, 270). De facto, nas células eucarióticas o gradiente de concentração de oxigénio diminui desde a membrana celular até à mitocôndria, consumindo a cadeia de transporte de electrões a maioria do oxigénio utilizado pela célula. Contudo, cerca de 2 a $5 \%$ desse oxigénio é transformado em ERO $(63,135$, 216), dependendo do substrato e do estadio de respiração. A eficiência do movimento de electrões através da cadeia de transporte de electrões e sua acoplação à fosforilação, para produzir adenosina trifosfato (ATP), é fundamental para a função mitocondrial, podendo ser determinada pela relação da produção de ATP por oxigénio molecular consumido e pelo estadio 3 ou 4 da respiração em que as mitocôndrias se encontram (135). Enquanto que, no estadio 3, a velocidade de fosforilação oxidativa não é limitada pela concentração de adenosina difosfato (ADP), no estadio 4, o nível de ADP limita a fosforilação oxidativa, estando associado a uma velocidade reduzida da cadeia respiratória e, consequentemente, a um aumento da formação de $\mathrm{O}_{2}{ }^{\cdot \cdot}(135,216)$. $\mathrm{O} \mathrm{O}_{2}{ }^{\bullet}$ formado na mitocôndria pode ser eliminado por uma enzima catalizada pela enzima Mn-Superóxido dismutase (Mn-SOD) sendo o $\mathrm{H}_{2} \mathrm{O}_{2}$ o produto final desta reacção. Este, poderá formar o $\mathrm{HO}^{\bullet}$, mediante a reacção com o $\mathrm{Cu}^{2+}$ ou com o $\mathrm{Fe}^{2+}$, mediante o ciclo de Haber Weiss, no interior da mitocôndria ou no citosol, após a sua difusão através das membranas mitocondriais $(65,82,83)$.

Devido à sua elevada reactividade, as ERO são capazes de modificar a maioria das moléculas biológicas (89). Por exemplo, a reacção do radical $\mathrm{HO}^{\bullet}$ com outras moléculas biológicas é altamente lesiva para a 
estrutura e funcionalidade celular, sendo responsável por danos nas moléculas de DNA, ao reagir com as bases purínicas e pirimídicas, por danos nas proteínas e por destruição das membranas, fruto da sua reacção com os ácidos gordos insaturados, propagando uma série de reacções de peroxidação lípidica ( 7 , $82,226,237,238$ ).

A propagação das reacções desencadeadas pelo radical superóxido pode passar pela sua reacção com o óxido nítrico $\left(\mathrm{NO}^{\bullet}\right)$, também produzido na mitocôndria, cujo composto resultante, o peroxinitrito

(ONOO) é altamente reactivo $(130,135)$. De facto, o papel atribuído inicialmente a estas espécies reactivas de nitrogénio (óxido nítrico, nitrato, nitrito, peroxinitrito e 3-nitrotirosina) nos processos de sinalização celular, na vasodilatação e na resposta imune é, agora, alargado ao campo das lesões oxidativas das biomoléculas. A confirmação da participação das espécies reactivas de nitrogénio em diversas patologias (hipertensão, doença de Alzheimer, incapacidade sexual e diminuição da resposta do sistema imune, entre outras) permite especular sobre o seu importante papel nos processos de envelhecimento $(116,192,194)$. A estimulação da enzima óxido nítrico sintetase mitocondrial parece, também, estar envolvida nos processos que desencadeiam a apoptose celular $(190,193,194)$.

As alterações induzidas nas mitocôndrias, como resultado da acção dos oxidantes formados na cadeia de transporte de electrões, podem ter efeitos nefastos cumulativos nas suas funções, constatados pela alteração do número, características morfológicas e actividade enzimática das mitocôndrias (89). Neste âmbito, têm sido observadas alterações histológicas nas mitocôndrias, nomeadamente o seu alongamento, vacualização da matriz, encurtamento das cristas e perda de grânulos densos (216). A par destas alterações regista-se, ainda, um aumento dos índices de peroxidação lipídica na membrana interna, tornando-a mais susceptível à perda de funcionalidade, o que contribui para a diminuição da relação estadio 3/estadio 4 e aumento da formação de $\mathrm{O}_{2}{ }^{\bullet}$ e $\mathrm{H}_{2} \mathrm{O}_{2}$ $(3,135,216)$. Estas alterações contribuem para a perda de eficiência da função mitocondrial com a idade $(3,216)$.

A constatação de que um número significativo de macromoléculas como o DNA $(2,24,116,256)$, as proteínas $(1,134,201,236,237,251)$ e os lípidos $(19,46,83,184)$ são lesadas pela acção das ERO, veio reforçar fortemente a hipótese da influência dos factores estocásticos na modificação dos componentes genéticos, com implicações no fenómeno de envelhecimento e em diversas patologias associadas à idade. Deste modo, todos os factores que induzem um aumento da formação de ERO poderão perturbar a homeostasia mitocondrial, contribuindo para o aumento de lesões e mutações neste organelo celular, com implicações ao nível da produção de energia e manutenção das funções vitais da célula $(11,12$, $58,126,229)$. Com efeito, a grande quantidade de mitocôndrias existentes em quase todas as células do corpo e a sua importância como organelo vital para a produção de energia, sustentam o argumento de que qualquer défice energético celular, causado por um declínio na função mitocondrial, pode condicionar a manutenção da actividade normal da célula e a sua capacidade de se adaptar a situações indutoras de stress fisiológico, tendo como resultado a maior susceptibilidade para desenvolver doenças específicas dos tecidos $(10,57,89,216,270,271)$. Os fenómenos do stress oxidativo e lesão mitocondrial tornam-se ainda mais importantes quando se considera o papel do seu genoma e das enzimas específicas, na transcrição e tradução de algumas proteínas. Os genes responsáveis pela síntese dos componentes peptídicos que intervêm na fosforilação oxidativa estão distribuídos pelo DNA mitocondrial (DNAmt) e pelo DNA nuclear (DNAn). Os componentes da cadeia de transporte de electrões trabalham como um sistema integrado, composto por um total de cinco complexos proteicos, dos quais o DNAmt codifica 13 proteínas e o DNAn 61 $(216,270,271)$. De facto, o DNAmt codifica sete polipeptídeos do complexo I, o que torna este complexo mais susceptível de erros estruturais, que poderão resultar numa diminuição da eficiência e consequente aumento da produção de ERO $(10,11)$. Ou seja, a ocorrência de erros no DNAmt vai originar a ocorrência de erros nos polipetídeos por ele codificados, que se traduzem na síntese de proteínas disfuncionais pertencentes aos complexos da cadeia respiratória mitocondrial. Nestas circunstâncias, vão ser produzidos mais ERO, com o consequente aumento das lesões do DNAmt, posterior formação 
de mais ERO e, possivelmente, apoptose celular (193). A velocidade de mutações no DNAmt é aproximadamente 17 vezes superior à que ocorre no DNAn $(270,272)$. É possível que a acumulação de todas as lesões no DNAmt possa contribuir para o aumento da disfunção, com a idade, na capacidade e função bioenergética mitocondrial. A perda temporária ou definitiva da função mitocondrial e da produção de ATP pode ter um impacto fundamental na manutenção da fidelidade das defesas celulares e processos de reparação, que podem resultar num aumento da carga mutacional, aumento da acumulação de macromoléculas celulares disfuncionais e diminuição da capacidade de responder adequadamente ao stress fisiológico. Ou seja, o aumento do stress oxidativo mitocondrial pode desencadear uma série de reacções em cadeia que terão como resultado o termo da vida da célula, possivelmente por apoptose ou autólise (175).

A hipótese da lesão oxidativa do DNA no fenómeno de envelhecimento é sustentada por evidências experimentais. Diversos estudos constataram um aumento dos níveis de 8-hidroxiguanina, um marcador da lesão oxidativa das bases guanina do DNA, com a idade $(2,12,83,140,202,256)$. A lesão oxidativa do DNA, leva a um declínio na função celular que poderá contribuir decisivamente para o fenómeno de envelhecimento e doenças degenerativas associados aos processos envelhecimento secundário, como o cancro $(4,140,255)$.

A oxidação das proteínas pode também ser um dos factores responsáveis pela presença de proteínas anormais nos animais mais idosos (61). Tem sido estabelecida uma relação positiva entre a idade do sujeito e a quantidade de grupos carbonilo proteicos, um indicador de lesão oxidativa das proteínas, encontrada em diversos tecidos e animais. Em vários modelos experimentais, a quantidade de grupos carbonilo variou de aproximadamente $2 \mathrm{nmol} / \mathrm{mg}$ de proteína nos sujeitos jovens até $3,5 \mathrm{a} 4,5 \mathrm{nmol} / \mathrm{mg}$ de proteína nos mais velhos $(164,229)$. Este aumento dos grupos carbonilo proteicos, em cerca de duas a três vezes com a idade, pode, à primeira vista, parecer pouco significativo. No entanto, os $2 \mathrm{nmol}$ de grupos carbonilo por mg de proteína observados nos mais jovens representam uma lesão de aproximadamente $10 \%$ da proteína celular total (239). No caso dos idosos, os valores obtidos poderão significar uma lesão de cerca de 20 a 30\% da proteína celular total (237). Estes resultados poderão estar sub-valorizados, uma vez que a modificação oxidativa de alguns resíduos de amino-ácidos nas proteínas não leva, forçosamente, à formação de grupos carbonilo $(237,238,240)$.

As cadeias longas de lípidos são, também, altamente susceptíveis de ser lesadas pelas ERO, podendo ocorrer reacções de peroxidação lipídica em cadeia $(46,83)$. Estas, consistem na degradação oxidativa dos ácidos gordos polinsaturados que se propaga para outras moléculas, mediante reacções em cadeia, podendo provocar a perda de estrutura e funcionalidade da membrana (46). A velocidade das reacções de peroxidação lipídica, observada em vários tecidos, depende da presença de factores antioxidantes e prooxidantes, de origem endógena ou exógena. Assim, o papel patogénico do processo de peroxidação lípidica é o resultado da degradação dos lipídos da membrana, da interacção dos produtos finais com alvos intra e extracelulares e da produção de novas ERO durante a cadeia de reacções (46). Os compostos não radicais, formados durante a degradação dos ácidos gordos, podem, ainda, ter um efeito lesivo nas estruturas biológicas, uma vez que sendo menos reactivos, conseguem atingir biomoléculas distantes do seu local de origem, com as quais estabelecem ligações covalentes $(46,82,83)$. Muitos produtos da peroxidação lipídica, como os aldeídos, são altamente reactivos e podem interagir directamente com o DNA e causar lesões $(46,83,117)$. O aumento da peroxidação lipídica com a idade é evidenciado pela acumulação progressiva do pigmento lipofuscina em muitos tecidos (61).

No organismo, em geral, o stress oxidativo parece variar com a concentração de oxigénio envolvente, com o tipo de tecido, o estado fisiológico, a dieta e a sua idade $(83,124)$. Diversos estudos constataram um aumento da formação de $\mathrm{O}_{2}{ }^{\bullet}$ e de $\mathrm{H}_{2} \mathrm{O}_{2}$ mitocondrial nos animais mais velhos $(173,176,230)$. Na mosca doméstica, Sohal e Sohal (230) constataram um aumento exponencial, que se cifrou em $100 \%$, na velocidade mitocondrial de produção de $\mathrm{H}_{2} \mathrm{O}_{2}$, entre o momento de maturação ( $4^{\circ}$ dia) e o pico da fase de morte rápida ( $\left.16^{\circ} \mathrm{dia}\right)$. Estes resultados foram, também, observados em Drosophilas mela- 
nogaster (231). Todavia, o nível de lesão celular causada pelas ERO depende, também, da capacidade de defesa dos antioxidantes, assim como, da capacidade de reparação celular. Isto é, os organismos aeróbios possuem sistemas de defesa orgânicos para proteger as suas células dos efeitos nocivos dos produtos do metabolismo oxidativo, transformando-os noutros produtos menos tóxicos ou não tóxicos $(16,124$, 130, 220). Um antioxidante é, por definição, qualquer substância que, quando presente em baixas concentrações relativamente às concentrações dos substractos oxidáveis, atrasa significativamente, ou inibe, a oxidação desses substratos por ERO (219, 220). Os antioxidantes compreendem sistemas enzimáticos e não enzimáticos, podendo a neutralização das ERO ser complementada por diversos antioxidantes $(72,124)$. Neste sentido, para confrontar as reacções potencialmente nefastas iniciadas pelo metabolismo oxidativo, os organismos possuem uma grande diversidade de mecanismos de defesa, que incluem a prevenção, a intercepção e a reparação $(124,219)$.

Os mecanismos de prevenção actuam de modo a evitar a formação de ERO. Neste grupo estão incluídas enzimas e moléculas que previnem a formação de compostos reactivos de oxigénio. São exemplos, as enzimas da cadeia respiratória que catalisam a redução do oxigénio a água sem que ocorra a formação de radicais livres de oxigénio, assim como as moléculas que ligam iões metálicos (ex. o ferro ligado à hemoglobina) e que impedem a participação livre destes iões em reacções do tipo Haber-Weiss (124). É possível que danos provocados nas enzimas implicadas nos processos de prevenção possam ser responsáveis pelo aumento da produção de ERO. Considerando, como exemplo, as enzimas da cadeia respiratória, é possível que erros na síntese destas enzimas contribuam para o aumento dos níveis de ERO formadas pela célula $(3,216)$. Como foi referido anteriormente, o aumento de ERO pode induzir, em situações extremas, a morte celular. Contudo, há sempre a possibilidade destes compostos reactivos serem interceptados por enzimas e moléculas antioxidantes. A intercepção das ERO é efectuada pelos mecanismos antioxidantes que protegem as células e tecidos dos efeitos negativos das ERO $(72,82,111,112$, 130, 214, 220). Os antioxidantes biológicos são um pré-requisito para a sobrevivência das células e incluem: 1) compostos enzimáticos, tais como a superóxido dismutase (SOD), a catalase (CAT) e a glutationa peroxidase (GPx); 2), moléculas que neutralizam os radicais hidrofílicos como o ascorbato, o urato, e a glutationa reduzida (GSH); 3) moléculas que neutralizam radicais lipofílicos como os tocoferois, flavonoides, carotenoides e ubiquinol; 4) enzimas envolvidas na redução de formas oxidadas de pequenos antioxidantes moleculares (glutationa redutase, dehidroascorbato redutase) ou responsáveis pela manutenção dos grupos tiol das proteínas (tioredoxina redutase); e 5) os mecanismos celulares que mantêm um meio reduzido (por exemplo, glucose-6-fosfato desidrogenase, que regenera o NADPH fosfato de dinucleótido de adenina nicotinamida) $(16,18,83,124,214,220)$. A forma como as defesas se complementam difere não só entre os organismos ou tecidos, mas também entre os compartimentos celulares. Por exemplo, a GPx tem um papel determinante nos mamíferos, mas está ausente nos insectos (232) e nemátodes (260); por outro lado, nos humanos existem três formas de SOD codificadas e reguladas independentemente (65). As principais enzimas antioxidantes presentes nos sistemas biológicos são a SOD, a GPx e a CAT (72, $83,124,214,220)$. Em situações de stress oxidativo intenso, estas enzimas são capazes de produzir espécies menos reactivas ou de neutralizar metabolitos do oxigénio reactivo (196). A SOD catalisa a dismutação do radical superóxido em peróxido de hidrogénio e oxigénio. A GPx utiliza a glutationa reduzida (GSH) para reduzir o $\mathrm{H}_{2} \mathrm{O}_{2}$ a glutationa oxidada e água. A CAT converte o $\mathrm{H}_{2} \mathrm{O}_{2}$ em água e oxigénio. De certo modo, há uma grande variabilidade destas defesas entre as espécies, mas a sua existência é universal entre os organismos aeróbios, o que sugere que a protecção contra os potenciais efeitos nocivos das ERO é essencial para a sobrevivência (18). Existem, nos mamíferos, três isoenzimas da SOD, sendo uma citosólica ( $\mathrm{Cu}, \mathrm{Zn}$-SOD ou SOD1), outra mitocondrial (Mn-SOD ou SOD2) e uma forma extracelular da Cu,Zn-SOD (ou SOD3) $(65,210)$. Nos mamíferos, a actividade da SOD total é maior no fígado e rins, tem uma actividade mais moderada no cérebro, coração, pâncreas e músculo esquelético e é muito reduzida nos eritrócitos (para refs. ver 
83). A distribuição das isoformas da SOD varia com o tecido. Assim, no músculo esquelético, 15 a $35 \%$ da actividade total da SOD está localizada nas mitocôndrias, estando os restantes 65 a $85 \%$ no citosol (133). A actividade total desta enzima varia, também, com as características histoquímicas do músculo esquelético, tendo os músculos com maior percentagem de fibras oxidativas maior actividade desta enzima, comparativamente com os músculos com menor capacidade oxidativa (i.e. maior percentagem de fibras tipo IIb) $(40,195,196)$.

A actividade da SOD está positiva e significativamente correlacionada com o tempo máximo de vida de diversas espécies de mamíferos (252). No entanto, quando se considera a mesma espécie animal, os resultados de estudos sobre as alterações da actividade da SOD com a idade divergem. Por exemplo, num estudo realizado por Ji (110), a actividade da $\mathrm{Cu}, \mathrm{Zn}$-SOD com a idade, diminuiu no coração e no fígado e aumentou no músculo esquelético. Todavia, a actividade da Mn-SOD aumentou nos três tecidos estudados, sugerindo a ocorrência de uma adaptação específica em certos compartimentos celulares ou em determinadas vias metabólicas. A especificidade das adaptações das isoenzimas da SOD foi também constatada em rim de rato, por Toshinai et al. (254), que descreveram uma diminuição da actividade da $\mathrm{Cu}, \mathrm{Zn}$-SOD com a idade e manutenção dos níveis de Mn-SOD. O aumento da actividade da SOD com a idade foi também confirmado, em diversos grupos musculares $(132,261)$. No fígado de ratinhos, a actividade desta enzima diminuiu significativamente com a idade (92). De um modo geral, e com excepção do músculo esquelético, parece haver uma diminuição da protecção dos diversos tecidos, pela SOD, com a idade.

Outra enzima determinante nos processos de neutralização das ERO é a GPx. Esta, dependente da presença de selénio, catalisa a redução do $\mathrm{H}_{2} \mathrm{O}_{2} \mathrm{e}$ outros hidroperóxidos $(\mathrm{ROOH})$, utilizando a glutationa reduzida (GSH) como dador de electrões, formando glutationa oxidada (GSSG) $(47,83,221$, 283). Esta característica atribui à GPx um papel importante na protecção celular das membranas lipídicas, proteínas e ácidos nucleicos contra as ERO. A GPx tem uma elevada actividade no fígado, uma actividade mais moderada no coração, rins, pulmões e cérebro, e baixa actividade nos músculos dos mamíferos $(83,221)$. Neste sentido, a actividade da GPx varia com o tipo de fibra muscular, sendo as fibras tipo I aquelas que possuem maior actividade desta enzima e as fibras tipo IIb as que têm menor actividade $(191,196)$. Tal como a SOD, também a GPx tem uma isoenzima mitocondrial e outra citosólica. No músculo esquelético, aproximadamente $45 \%$ da actividade da GPx é encontrada no citosol, estando os restantes $55 \%$ na mitocôndria $(111,112)$. Esta localização mitocondrial e citoplasmática permite à GPx estar próxima das diversas fontes de formação de hidroperóxidos. A GPx é a única enzima antioxidante conhecida capaz de reduzir o $\mathrm{H}_{2} \mathrm{O}_{2}$ produzido pela Mn-SOD, uma vez que a maioria das mitocôndrias existentes em células de mamíferos não possuem actividade da catalase (6). A mitocôndria possui dois tipos de enzimas com função de peroxidase, a glutationa peroxidase clássica (GPx) e a fosfolípido hidroperóxido glutationa peroxidase, sendo esta a única enzima intracelular conhecida capaz de reduzir directamente os fosfolípidos peroxidados e o colesterol das membranas (6).

A modulação da actividade desta enzima com a idade é específica, não só dos tecidos, como também dos compartimentos celulares. Assim, no coração, a GPx diminui significativamente com a idade no citosol mas aumenta na mitocôndria (110), revelando adaptações específicas causadas, possivelmente, pelo aumento da produção de ERO nas mitocôndrias dos ratinhos mais velhos. A GPX aumenta com a idade na aorta (49), no fígado $(110,227)$ e no músculo esquelético $(110,130,132)$.

Para além da GPx, a redução dos hidroperóxidos orgânicos pela GSH pode também ser catalisada por uma enzima independente de selénio, a glutationa Stransferase (GST) $(155,273)$. A GST constitui uma família de enzimas, independentes de selénio, que pode actuar, quer como peroxidase, quer como transferase $(103,155,273)$. A actividade de peroxidase pode ser particularmente importante na redução de hidroperóxidos orgânicos, enquanto que a actividade de transferase parece amplamente envolvida na desintoxicação através da glutationa (83). Nos insectos, a ausência de GPx é colmatada pela existência da enzima GST que desempenha a função de peroxidase (183). Nos ratinhos, a idade é acom- 
panhada por um aumento da actividade desta enzima no músculo esquelético (132) e diminuição no fígado (110).

A funcionalidade da GPx está dependente da existência de GSH como dador de electrões. Uma vez que a GSH é oxidada pela GPx, formando GSSG, as células possuem a enzima glutationa redutase (GR) capaz de regenerar a GSH a partir da GSSG $(48,155,273)$. A glutationa redutase (GR) contém duas sub-unidades proteicas, cada uma contendo uma flavina (dinucleótido de flavina e adenina - FAD) no seu local activo (83). Aparentemente, o NADPH reduz a FAD, que passa então os seus electrões para uma ponte persulforeto (-S-S-) entre dois resíduos de cisteína na proteína. Os dois grupos - $\mathrm{SH}$, então formados, reagem com a GSSG e reduzem-na a $2 \mathrm{GSH}(48,83,155$, 273). Em muitos tecidos animais, o NADPH necessário para que ocorra a redução da GSSG é fornecido pela via das pentoses fosfato, pela oxidação do malato em piruvato, pela enzima extramitocondrial malato desidrogenase, ou pela conversão do isocitrato em $\alpha$-cetoglutarato, através da acção da isocitrato desidrogenase citoplasmática (84).

A distribuição celular da GR é semelhante à da GPx, sendo a sua actividade maior nos músculos predominantemente oxidativos (196). Apesar da GR não ser considerada uma enzima antioxidante, ela é essencial para o normal funcionamento antioxidante. $\mathrm{O}$ processo de envelhecimento é acompanhado por um aumento da actividade desta enzima $(110,132)$. Outra enzima que catalisa a decomposição do $\mathrm{H}_{2} \mathrm{O}_{2}$ em $\mathrm{H}_{2} \mathrm{O}$ e $\mathrm{O}_{2}$ é a CAT. A actividade desta enzima nos tecidos animais e em plantas está largamente localizada nos peroxissomas $(83,147,203)$. Estes organelos celulares contêm, também, algumas enzimas que formam $\mathrm{H}_{2} \mathrm{O}_{2}$ celular, como a glicolato oxidase, a urato oxidase e a flavoproteína desidrogenase envolvida na $\beta$-oxidação dos ácidos gordos (147). As mitocôndrias (pelo menos no fígado) e o retículo endoplasmático contêm pouca ou nenhuma actividade da CAT, pelo que qualquer $\mathrm{H}_{2} \mathrm{O}_{2}$ formado in vivo nestes organelos não poderá ser regulado por esta via $(83,111,112)$. No entanto, tem sido referido que a mitocôndria de cardiomiócitos de rato contém alguma actividade na matriz (83).

Na generalidade dos animais, a CAT está presente em praticamente todos os órgãos, estando particu- larmente concentrada no fígado e eritrócitos (83). O cérebro, o coração e os músculos esqueléticos contêm pequenas quantidades, sendo, no entanto, a sua actividade muito variável nos diversos músculos e em diferentes regiões do mesmo músculo (83). Tal como a SOD e a GPx, a actividade da CAT é mais elevada nos músculos com predominância de fibras oxidativas e mais reduzida nos músculos com uma grande percentagem de fibras glicolíticas (196). A alteração da actividade da CAT com a idade não é uniforme nos diferentes tecidos. De facto, a sua actividade aumenta com a idade no músculo esquelético $(110,132)$ e no cérebro (227), diminui no rim (254) e na aorta (49) e não se altera no fígado e no coração (110).

Os estudos referidos não permitem concluir que o fenómeno de envelhecimento esteja associado a uma diminuição das enzimas antioxidantes, uma vez que as alterações observadas variam com o tecido estudado, com a especificidade da isoenzima e organelo celular analisado e, possivelmente, com a técnica utilizada para a determinação da actividade enzimática $(49,110,132,227,254)$.

No músculo esquelético, a actividade das enzimas antioxidantes tende a aumentar com a idade (110, $132,261)$. Este facto poderá estar relacionado com as alterações que ocorrem, com a idade, nas fibras musculares (diminuição do número e atrofia das fibras musculares com características glicolíticas), que resultam num aumento percentual da expressão das fibras oxidativas $(26,139,247,250,259)$. O aumento das ERO com a idade poderá, também, ser responsável pelo aumento da actividade das enzimas antioxidantes $(192,253)$.

Noutros tecidos analisados, as alterações observadas na actividade das enzimas antioxidantes não são uniformes, tendo sido descritas alterações de isoenzimas específicas, nomeadamente nas mitocondriais, o que sugere um aumento da disfunção mitocondrial e, consequentemente, aumento da formação de ERO $(3,110,132,216)$.

A impossibilidade de estudar a influência das defesas antioxidantes e a longevidade, no organismo como um todo, levou diversos investigadores a recorrer a modelos de estudo mais simples, como as leveduras, os nemátodes e os insectos $(106,107$, $108,125,128,141,158,181,246,248)$. Nestas 
espécies animais têm sido frequentemente utilizados modelos transgénicos para o estudo da verdadeira participação de um ou mais mecanismos antioxidantes no fenómeno de envelhecimento. Ou seja, se as ERO forem, de facto, um factor determinante neste fenómeno, então o aumento das defesas antioxidantes deverá diminuir o stress oxidativo e aumentar a longevidade. Por outro lado, a redução ou eliminação das mesmas deverá diminuir os indicadores de longevidade. A utilização de miméticos das enzimas antioxidantes e as mutações induzidas que resultaram num aumento da expressão de enzimas antioxidante em leveduras (Saccharomyces cerecisiae) (106, 107, 108), em nemátodes (Caenorhabiditis elegans) $(125,128,141,158,246,248)$, em moscas (Drosophilas melanogaster) (181) e em ratos $(13,27$, $79,157,159)$ foram acompanhados por uma longevidade superior. Por exemplo, o aumento da expressão da SOD, da CAT e de proteínas de stress, mediante o recurso a métodos transgénicos, aumentou significativamente a longevidade de Drosophilas melanogaster (181, 243, 245). Esta correlação positiva, entre os mecanismos antioxidantes e a longevidade, sustentam a "Teoria do Stress Oxidativo" como base para explicar o fenómeno de envelhecimento. Para além das enzimas antioxidantes, os organismos aeróbios possuem, também, mecanismos não enzimáticos antioxidantes, lipofílicos (vitamina $\mathrm{E}, \beta$ carotenos, ubiquinona e ubiquinol e flavonoides) e hidrofílicos (vitamina C e glutationa), que (i) previnem a formação de radicais, (ii) neutralizam as ERO ou convertem-nas em espécies menos activas, (iii) participam na reparação dos danos iniciados pelos radicais e (iv) participam, em conjunto com outros agentes, na manutenção do equilíbrio do estado redox da célula (72). A capacidade antioxidante depende, não só do papel específico de cada mecanismo antioxidante, como também da cooperação entre os mesmos, de modo a proteger a célula dos potenciais efeitos nefastos das ERO. Por exemplo, as reservas de grupos $-\mathrm{SH}$ da glutationa reduzida (GSH) têm um papel central na regeneração das formas radicais das vitaminas C e E (213).

A glutationa é um tripéptido (L- $\gamma$-glutamil-L-cisteinil-glicina) com uma representação de pelo menos $90 \%$ do total dos grupos -SH não proteicos, encontrada em praticamente todas as células aeróbias
$(155,214)$. Tem diversas funções fisiológicas e metabólicas importantes que incluem a neutralização de ERO e de outros compostos electrofílicos (199, 273). A concentração intracelular de glutationa mantém-se entre os 0,5 e $10 \mathrm{mM}$, sendo a sua concentração extracelular normalmente 3 a 4 vezes mais baixa (199, 273). Em condições fisiológicas, a GR mantém mais de $98 \%$ da GSH intracelular no estado reduzido, o que contribui significativamente para manter o estado reduzido do meio intracelular $(48,111,112$, 273). A restante glutationa está presente na célula como persulforetos mistos (GS-S-proteína e GSSG) e como tioesters (273). A maioria da glutationa, in vivo, está presente numa concentração 10 vezes superior como GSH, comparativamente à concentração de GSSG (83). Entre 10 a $15 \%$ da GSH total intracelular está localizada na mitocôndria, estando o restante no citosol $(47,58)$. Na generalidade, todas as células que contêm glutationa são capazes de a sintetizar em duas etapas, catalisadas pelas enzimas $\gamma$-glutamil-cisteina sintetase (cataliza a ligação do L-glutamato à L-cisteína) e pela GSH sintetase (liga a glicina ao dipeptido L- $\gamma$-glutaminl-L-cisteinil) (273). A inexistência de enzimas necessárias à síntese de GSH na mitocôndria implica que este organelo tenha de importar GSH do citosol $(48,257$, 273) através de transportadores específicos existentes na membrana interna mitocondrial $(59,196)$. Apesar de em condições fisiológicas a GR ser muito eficiente, mantendo a maioria da GSH no estado reduzido, em situações de stress oxidativo intenso, ou quando a actividade da GR está danificada, a capacidade de reduzir a GSSG pode ser excedida, levando à acumulação intracelular deste metabolito $(111,112,214)$. Nestas condições, a célula pode transportar activamente GSSG para o seu exterior, de modo que os níveis intracelulares se mantenham baixos comparativamente com os de GSH $(118,119$, 197). No entanto, a mitocôndria não consegue exportar GSSG, de modo que o aumento acentuado de GSSG poderá tornar este organelo particularmente susceptível a lesões (48). A acumulação de GSSG intramitocondrial parece ser mesmo uma etapa importante da morte celular $(83,200)$.

A exportação de GSSG pela célula tem como objectivo prevenir a inibição da actividade catalítica de enzimas importantes do metabolismo energético que 
poderá comprometer a viabilidade celular $(83,257$, 273). De facto, diversas enzimas do metabolismo da glicose, tais como a glicogénio sintetase, a piruvato cinase e a fosfofrutocinase, são inibidas na presença de elevadas concentrações de GSSG $(25,83,273)$. Por outro lado, a frutose-1,6-difosfatase é activada pela formação de GSSG $(25,273)$ estimulando a via das pentoses fosfato, muito menos rentável do ponto de vista energético comparativamente à glicólise. Deste modo, devido ao comportamento oposto destas enzimas com o estado redox da célula, a glicose6-fosfato é metabolizada pela via glicolítica em condições de redução, enquanto que, em condições de oxidação, ela é canalizada para a via das pentoses fosfato para a produção de NADPH (25). Assim, à medida que a GR actua, a relação NADPH/NADP ${ }^{+}$ diminui e aumenta a degradação da glicose-6-fosfato pela via das pentoses fosfato para restabelecer os níveis de NADPH (25). O stress oxidativo prolongado levará à produção e consumo permanente de NADPH à custa da glicose-6-fosfato, que deverá ser canalizado para um ciclo fútil. A mudança, no metabolismo da glicose, da glicólise para o ciclo das pentoses pode ter consequências incompatíveis com a sobrevivência da célula (25).

A exportação de GSSG parece funcionar também como parte de um sistema que visa proteger a célula, nomeadamente as membranas celulares, das reacções de peroxidação lipídica (19). De facto, a diminuição dos níveis de GSH e consequente diminuição da relação GSH/GSSG é seguida de perturbações na homeostasia do cálcio, peroxidação lipídica e alterações ultra-estruturais da célula (222).

Outra função da GSH intracelular é a redução de vários antioxidantes à sua estrutura natural, como por exemplo a redução do radical da vitamina $E$ ( $\alpha$ tocoferoxil) $(83,283)$ e do radical semi-dehidroascorbato (radical da vitamina $\mathrm{C}$ ) dehidrolipoato (52, $72,152)$. Este pode ter um papel importante na regeneração do ácido ascórbico $(83,283)$. Em conjunto, estas reacções regeneram eficientemente a vitamina $\mathrm{E}$ e C com o gasto da GSH.

Poucos trabalhos têm estudado a variação da glutationa com a idade. Como acontece com as enzimas antioxidantes, também no músculo esquelético (soleus) de ratinhos foram observados aumentos significativos da GSH, glutationa total e da relação
GSH/GSSG com a idade (132). Neste estudo, o conteúdo da GSSG não se alterou com a idade. Estes resultados poderão, no entanto, estar exagerados, na medida em que foram expressos em função do conteúdo proteico, o qual evidenciou uma diminuição com a idade. Assim, o parâmetro que melhor expressa, neste estudo, a variação do stress oxidativo é a rácio GSH/GSSG. Num estudo em Drosophilas melanogaster, a concentração de GT esteve positivamente correlacionada com a idade (168), sugerindo a existência de modulação deste antioxidante com o fenómeno de envelhecimento. Isto é, o fenómeno de envelhecimento, por si só, parece induzir um aumento da produção de ERO, que deverá ter induzido um aumento da síntese de GT para a sua neutralização. O aumento da GT com a idade, poderá ser explicado por um aumento da actividade das enzimas que sintetizam este tripétido ( $\gamma$-glutamil-cisteina sintetase e GSH sintetase), sensíveis ao aumento da produção de ERO $(196,215)$. Neste grupo, os valores do ratio GSSG/GT e da concentração de GSSG também aumentaram com a idade, insinuando um possível aumento do stresse oxidativo.

Apesar da existência dos diversos sistemas antioxidantes, algumas ERO escapam à sua neutralização e provocam danos nas células. Consoante a dimensão da lesão, a célula opta por desencadear os mecanismos de reparação ou pelo suicídio.

A reparação inclui a remoção total ou parcial da molécula lesada, seguida da sua substituição (47, 124). Nas células eucarióticas, existem múltiplos sistemas enzimáticos envolvidos na reparação do DNA oxidado (p.e. glicosilases e endonucleases) $(50,102$, $177,242)$, na reparação das membranas oxidadas (p.e. fosfolipases $\mathrm{A}_{2}$ e $\mathrm{C}$ e peroxidases citosólicas envolvidas no metabolismo dos hidroperóxidos lipídicos) $(47,208)$ e na reparação das proteínas oxidadas (p.e. proteases citosólicas e proteínas de stress) $(237,263)$. O aumento do stress oxidativo pode activar os factores de transcrição sensíveis às ERO (212), induzindo um aumento da síntese de enzimas intervenientes nos processos de defesa e na remoção de moléculas lesadas ou produtos resultantes da sua oxidação (182). A detecção de elevados níveis de marcadores de lesão oxidativa nos animais envelhecidos, comparativamente aos congéneres mais jovens $(12,223,239,277,282)$, tem sido atribuída, por um 
lado, ao aumento da produção de ERO com a idade descrita anteriormente e, por outro, à diminuição da velocidade da sua remoção e substituição $(15,32$, $47,69,78,138,182,223,239,263)$.

Tal como nas teorias genéticas, também entre as teorias estocásticas a divisão das teorias limita o conhecimento do processo de envelhecimento. De facto, o mesmo factor estocástico pode induzir alterações em diversos mecanismos subjacentes ao fenómeno de envelhecimento. Por exemplo, considerando a influência das radiações na longevidade, os seus efeitos fazem-se sentir não só ao nível da alteração metabólica, aumentando o stress oxidativo, como também ao nível da alteração de factores que regulam os ciclos celulares. A interligação entre as diferentes teorias é também evidente quando se considera o papel das reacções de glicosilação nas proteínas, ao destruir enzimas como a $\mathrm{Cu}, \mathrm{Zn}$-SOD, diminuindo, consequentemente, a capacidade antioxidante. $\mathrm{O}$ excesso de glicose, responsável pelas reacções de glicosilação, pode, também, levar a um aumento do metabolismo oxidativo e consequentemente a um aumento da formação de espécies reactivas de oxigénio.

Os mecanismos biológicos actuam de uma forma coordenada e equilibrada, de modo que quando um sistema é perturbado, muitos outros também o são. É necessário ter consciência desta inter-relação entre os factores que influenciam o envelhecimento, ou são dele consequência. Assim, a divisão das teorias biológicas deverá ser entendida no contexto das variáveis que se pretende estudar e não como a explicação isolada do processo de envelhecimento.

\section{CORRESPONDÊNCIA}

Maria Paula Mota

Departamento de Desporto

Universidade de Trás-os-Montes e Alto Douro

Rua Dr. Manuel Cardona, CIFOP

5000 Vila Real, Portugal

mpmota@utad.pt 


\section{REFERÊNCIAS}

1. Adams, S., Green, P., Claxton, R., Simcox, S., Williams, M.V., Walsh, K., Leeuwenburgh, C. (2001) Reactive carbonyl formation by oxidative and non-oxidative pathways. Frontiers in Bioscience, 6: 17-24.

2. Agarwal, S., Sohal, R.S. (1994) DNA oxidative damage and life expectancy in houseflies. Proc. Natl. Acad. Sci. USA. 91: 12332-12335.

3. Ames, B.N., Shigenaga, M.K., Hagen, T.M. (1993) Oxidants, antioxidants, and the degenerative diseases of aging. Proc. Natl. Acad. Sci. USA., 90: 7915-7922.

4. Ames, B.N., Gold, L.S. (1991) Endogenous mutagens and the causes of aging and cancer. Mutat. Res. 250: 3-16.

5. Arai, K., Maguchi, S., Fujii, S., Ishibashi, H., Oikawa, K., Taniguhi, N. (1987) Glycation and inactivation of human $\mathrm{Cu}, \mathrm{Zn}$-Superoxide dismutase. Identification of the in vitro glycated sites. J. Biol. Chem., 262: 16969-16972.

6. Arai, M., Imai, H., Koumura, T., Yoshida, M., Emoto, K., Umeda, M., Chiba, M., Nakagawa, Y. (1999) Mitochondrial phospholipid hydroperoxide glutathione peroxidase plays a major role in preventing oxidative injury to cells. J. Biol. Chem. 274 (8): 4924-4933.

7. Araki, M., Nanri, H., Ejima, K., Murasato, Y., Fujiwara, T., Nakashima, Y., Ikeda, M. (1999) Antioxidant function of the mitochondrial protein SP-22 in the cardiovascular system. J. Biol. Chem. 274 (4): 2271-2278.

8. Arking, R., Buck, S., Wells, R., Pretzlaff, R. (1988) Metabolic rates in genetically based long-lived strains of Drosophila. Exp. Gerontology, 23: 59-76.

9. Atalay, M., Laaksonen, D.E. (2002) Diabetes, oxidative stress and physical exercise. J. Sports Sci. Med., 1: 1-14.

10. Bandy, B., Davidson, A. (1990) Mitochondrial mutations may increase oxidative stress: implications for carcinogenesis and aging? Free Rad. Biol. Med., 8: 523-539.

11. Barja, G., Cadenas, S., Rojas, S., Perez-Campo, R., LopezTorres, M. (1994) Low mitochondrial free radical production per unit $\mathrm{O} 2$ consumption can explain the simultaneous presence of high longevity and high aerobic metabolic rate in birds. Free Radical Research, 21: 317-327.

12. Barja, G., Herrero, A. (2000) Oxidative damage to mitochondrial DNA is inversely related to maximum life span in the heart and brain of mammals. FASEB J. 14: 312-318

13. Bartke, A., Coschigano, K., Kopchick, J., Chandrasshekar, V., Mattison, J., Kinney, B., Hauck, S. (2001) Genes that prolong life: relationships of growth hormone to aging and life span. J. Gerontology (Biol. Sci.), 56A (8): B340-B349.

14. Barzilai, N., Banerjee, S., Hawkins, M., Chen, W., Rossetti, L. (1998) Caloric restriction reverses hepatic insulin resistance in aging rats by decreasing visceral fat. J Clin Invest, 101:1353-1361.

15. Barzilai, A., Rotman, G., Shiloh Y. (2002) ATM deficiency and oxidative stress: a new dimension of defective response to DNA damage. DNA Repair, 1: 3-25.

16. Bast, A., Haenen, G.R., Doelman, C.J. (1991) Oxidants and antioxidants: State of the art. American J. Med. 91 (suppl 3C): 3C-2S - 3C-13S.

17. Becerro, J.F, Miquel, J. (2002) Mitocondrias, envejecimento, músculo y ejercicio. Arch. Med. del Deporte, XIX (89): 231-244.

18. Beckman, K.B., Ames, B.N. (1998) The free radical theory of aging matures. Physiological Reviews, 78 (2): 547-581.
19. Benzi, G., Moretti, A. (1995) Age- and peroxidative stressrelated modifications of the cerebral enzymatic activities linked to mitochondria and glutathione system. Free Rad. Biol. Med., 19 (1): 77-101.

20. Beshyah, S., Henderson, A., Niththyanathan, R., Skinner, E., Anyaoku, V., Richmond, W., Sharp, P., Johnson, D. (1995) The effects of short and long term growth hormone replacement therapy in hypopituitary adults on lipid metabolism and carbohydrate metabolism. J Clin Endocrin Metab. 83: 356-363.

21. Blackburn, E.H. (1990) Telomeres sans frontieres. Nature, 343: 122 .

22. Blackburn, E.H. (1997) The telomere and telomerase: Nucleic acid - protein complexes acting in a telomere homeostasis system. A review. Biochemistry, 62 (11): 11961202.

23. Bowen, I.D., Bowen, S.M., Jones, A.H. (1998) Mitosis and Apoptosis: Matters of life and death. Londres: Chapmam \& Hall.

24. Breen, A.P., Murphy, J.A. (1995) Reactions of oxyl radicals with DNA. Free Rad. Biol. Med. 18 (6): 1033-1077.

25. Brigelius, R. (1985) Mixed disulfides: biological functions and increase in oxidative stress. In H. Sies (Ed.) Oxidative Stress. Londres: Academic Press, 243-272.

26. Brooks, G.A., Fahey, T.D., White, T.P. (1996) Exercise physiology: Human bioenergetics and its applications. Londres: Mayfield Publishing Company.

27. Brown-Borg, H.M., Borg, K.E., Meliska, C.J., Bartke, A. (1996) A Dwarf mice and the ageing process. Nature, 384: 33.

28. Brown-Borg, H.M., Bode, A.M., Bartke, A (1999) Antioxidant mechanisms and plasma growth hormone levels. Endrocrine, 11: 41-48.

29. Bunn, F., Higgins, P.J. (1981) Reaction of monosaccharides with proteins: possible evolutionary significance. Science. 213: 222-224.

30. Bunn, F., Seal, U.S., Scott, A.F. (1974) The role of 2,3diphosphoglycerate in mediating hemoglobin function of mammalian red cells. Ann. N.Y. Acad. Sci. 241: 498-512.

31. Burnet, M. (1974) Intrinsic Mutagenesis: A genetic approach. New York: Wiley.

32. Carney, J.M, Starke-Reed, P.E., Oliver, C.N., Landum, R.W. Cheng, M.S., Wu, J.F., Floyd, R.A. (1991) Reversal of agerelated increase in brain protein oxidation, decrease in enzyme activity and loss of temporal and spatial memory by chronic administration of the spin-trapping compound N-tert-butyl-alfa-phenylnitrone. Proc. Natl. Acad. Sci. USA, 88: 3633-3636.

33. Carrel, A. (1921) On the permanent life of tissue outside of the organism. J. Exp. Med, 34: 599-623.

34. Cech, T.R. (1994) Chromosome end games. Science. 266: 387-388.

35. Cerami, A. (1985) Hypothesis: glucose as a mediator of aging. J. Am. Geriatric Soc. 33: 626-634.

36. Cerami, A., Vlassara, H., Brownlee, M. (1987) Glucose and aging. Sci. Am. 256: 90-96.

37. Chang, R. (1994) Química. Lisboa: McGraw-Hill.

38. Chen, M., Bergman, R.N., Porte, D. (1988) Insulin resistance and B-cell dysfunction in aging: the importance of dietary carbohydrate. J. Clin. Endocrinol. Metab. 67: 951957. 
39. Cristofalo, V.J., Gerhard, G.S., Pignolo, R.J. (1994) Molecular biology of aging. Surg. Clin. North Am., 74: 1-21.

40. Criswell, D., Powers, S., Dodd, S., Lawler, J., Edwards, W. (1993) High intensity training-induced changes in skeletal muscle antioxidant enzyme activity. Med. Sci. Sports Exer. 25: 1135-1140.

41. Curtis, H. (1963) Biological mechanisms underlying the aging process. Science, 141: 686-694.

42. Curtis, H. (1966) Biological mechanisms of aging. Springfield, IL: C.C. Thomas.

43. Curtsinger, J.W., Fukui, H.H., Khazaeli, A.A., Kirscher, A., Pletcher, S.D., Promoislow, D.E., Tatar, M. (1995) Genetic variation and aging. Annu. Rev. Genetics. 29: 553-575.

44. Cutler, R.G. (1986) Aging and oxygen radicals. In: A.E. Taylor, S. Matalon e P. Ward (eds.) Physiology of oxygen radicals. (vol. 2, pp: 19-38). American Physiological Society.

45. Cutler, R.G. (1991) Antioxidants and aging. Am. Soc. Clin. Nut.. 53: 3735-3795.

46. Dargel, R. (1992) Lipid peroxidation - a common pathogenetic mechanism? Exp Toxic Pathol, 44: 169-181.

47. Davies, K.J., Wise, A.G., Sevanian, A., Kim, E.H. (1990) Repair systems in oxidative stress. In C. E. Finch, T. E. Johnson (Eds.) Molecular Biology of Aging. Nova York: Wiley-Liss, 123-141.

48. DeLeve, L., Kaplowitz, N. (1991) Glutathione metabolism and its role in hepatotoxicity. Pharmacol. Ther. 52 (3): 287 305.

49. Demaree, S.R., Lawler, J.M., Linehan, J., Delp, M.D. (1999) Ageing alters aortic antioxidant enzyme activities in Fischer-344 rats. Acta Physiol. Scand. 166: 203-208.

50. Demple, B., Harrison, L. (1994) Repair of oxidative damage to DNA: enzymology and biology. Annu. Rev. Biochem. 63: 915-948.

51. Dills, W.L. (1993) Protein frutosylation: fructose and Maillard reaction. Am. J. Clin. Nutr. 58 (Suppl 5): 779S787s.

52. Di Mascio, P., Murphy, M.E., Sies, H. (1991) Antioxidant defense systems: the role of carotenoids, tocoferols, and thiols. Am. J. Clin. Nutr. 53: 194S-200S.

53. Donlin, M., Patel, S., Johnson, K. (1991) Kinetic partitioning between the exonuclease and polymerase sites in DNA error correction. Biochemistry, 30: 538-546.

54. Drew, B., Leeuwenburgh, C. (2002) Aging and role of reactive nitrogen species. Ann N Y Acad. Sci. 959: 66-81.

55. Edelmann, P., Gallant, J. (1977) On the translational error theory of aging. Proc. Natl. Acad. Sci. USA, 74: 3396-3398

56. Ernst, D.N., Hobbs, M.V., Torbett, B.E., Glasebrook, A.L., Rehse, M.A., Bottomly, K., Hayakawa, K., Hardy, R.R., Weigle, W. (1990) Differences in the expression profiles of CD45RB, Pgp-1, and 3G11 membrane antigens and in the patterns of lymphokine secretion by splenic $\mathrm{CD} 4^{+} \mathrm{T}$ cells from young and aged mice. J. Immunology, 145 (5): 1295 1302 .

57. Esposito, L., Melov, S., Panov, A., Cottrell, B., Wallace, D. (1999) Mitochondrial disease in mouse results in increased oxidative stress. Proc. Natl. Acad. Sci. USA, 96: 48204825 .

58. Esteve, J.M., Mompo, J., Asuncion, J.G., Sastre, J., Asensi, M., Boix, J., Viña, J.R., Viña, J., Pallardó, F.V. (1999) Oxidative damage to mitochondrial DNA and glutathione oxidation in apoptosis: studies in vivo and in vitro. FASEB J., 13: 1055-1064.
59. Fernandez-Checa, J.C., Kaplowitz, C, Garcia-Ruiz, C., Colell, A., Miranda, M., Marí, M., Ardite, E., Morales, A. (1997) GSH transport in mitochondria: defense against TNF-induced oxidative stress and alchol induced defect. Am. J. Physiol. 273: G7-G17.

60. Finch, C.E. (1976) The regulation of physiological changes during mammalian aging. Q. Rev. Biol., 51: 49-83.

61. Finch, C.E. (1994) Longevity, Senescence, and the Genome. Chicago: University of Chicago Press.

62. Fong, T.C., Makinodan, T. (1989) In situ hybridization analysis of the age-associated decline in IL-2 mRNA expressing murine T cells. Cellular Imunnology, 118: 199 207.

63. Forman, H., Boveris, A. (1982) Superoxide radical and hydrogen peroxide in mitochondria. In W. A. Pryor (Ed.) Free Radicals in Biology (Vol. V). New York: Academic Press, 65-90.

64. Frei, B. (1999) Molecular and biological mechanisms of antioxidant action. FASEB J. 13: 963-964.

65. Fridrovich, I. (1995) Superoxide radical and superoxide dismutases. Annu. Rev. Biochem., 64: 97-112.

66. Fujita, M. (1999) Cell cycle regulation of DNA replication initiation proteins in mammalian. Frontiers in Bioscience, 4 : d816-823.

67. Fukuchi, K., Martin, G.M., Monnat, R.Jr. (1989) Mutator phenotype of Werner syndrome is characterized by extensive deletions. Proc. Natl. Acad. Sci. USA., 86: 5893-5897.

68. Gaivão, I. (1999) Avaliação genotoxica de compostos indutores de espécies reactivas de oxigénio: um estudo em Drosophila melanogaster. Tese de Doutoramento, Universidade de Trás-os-Montes e Alto Douro, Vila Real (não publicado).

69. Gershon, H., Gershon, H. (1970) Detection of inactive enzyme molecules in ageing organisms. Nature, 227: 12141217.

70. Giulivi, C., Cadenas, E. (1998) The role of mitochondrial glutathione in DNA base oxidation. Bioch. Biophy. Acta, 1366:265-274.

71. Goldberg, A.P., Coon, P.J. (1987) Non-insulin-dependent diabetes mellitus in the elderly. Influence of obesity and physical inactivity. Endocrinol. Metab. Clin. 16: 843-865.

72. Goldfarb, A.H. (1999) Nutritional antioxidants as therapeutic and preventive modalities in exercise-induced muscle damage. Can. J. Appl. Physiol. 24 (3): 249-266.

73. Goukassian, D., Gad, F., Yaar, M., Eller, M.S., Nehal., U.S. Gilchrest, B.A. (2000) Mechanisms and implications of the age-associated decrease in DNA repair capacity. FASEB J., 14: $1325-1334$

74. Greider, C.W., Blackburn, E.H (1985) Identification of a specific telomere terminal transferase activity in Tetrahymena extracts. Cell. 43: 405-413.

75. Greider, C.W., Blackburn,E.H (1987) The telomere terminal transferase of Tetrahymena is a tibonucleoprotein enzyme with two kinds of primer specifictiy. Cell, 51: 887-898.

76. Greider, C.W., Blackburn, E.H (1989) A telomeric sequence in the RNA of Tetrahymena telomerase required for telomere repeat synthesis. Nature. 337: 331-337.

77. Greider, C.W., Blackburn, E.H (1996) Telomeres, telomerase and cancer. Sci. Am, 92-97.

78. Grune, T., Shringarpure, R., Sitte, N., Davies, K. (2001) Age-related changes in protein oxidation and proteolysis 
in mammalian cells. J. Gerontol. (Biol. Sci.), 56A (11): B459-B467.

79. Guarente, L. (1999) Mutant mice live longer. Nature. 402: 243-245.

80. Guarente, L., Kenyon, C. (2000) Genetic pathways that regulate ageing in model organisms. Nature, 408: 255-262.

81. Hackett, J.A., Feldser, D.M., Greider, C.W. (2001) Telomere dysfunction increases mutation rate and genomic instability. Cell, 106: 275-286.

82. Halliwell, B. (1991) Reactive oxigen species in living systems: Source, biochemistry, and the role in human disease. American J. Med. 91 (suppl 3C): 3C-14S -3C-22S.

83. Halliwell, B., Gutteridge, J.M.C. (1989) Free radicals in biology and medicine. Londres: Clarendon Press.

84. Halpern, M.J. (1997) Bioquímica. Lisboa: LIDEL.

85. Hamilton, M.L., Remmen, H.V., Drake, J., Yang, H., Guo, Z.M., Kewitt, K., Walter, C.A., Richardson, A. (2001) Does oxidative damage to DNA increase with age? PNAS, 98 (18): 10469-10474.

86. Hanawalt, P.C., Gee, P., Ho, L. (1990) DNA repair in differentiating cells in relation to aging. In C.E. Finch e T.E. Johnson (Eds.) Molecular Biology of Aging. Nova York: Wiley-Liss, 45-51.

87. Harley, C.B., Pollard, J.W., Chamberlain, J.W., Stanners, C.P., Goldstein, S. (1980) Protein synthetic errors do not increase during aging of cultured human fibroblasts. Proc. Natl. Acad. Sci. USA, 77 (4): 1885-1889.

88. Harman, D. (1956) Aging: a theory based on the free radical and radiation chemistry. J. Gerontol. 11: 298-300.

89. Harman, D. (1991) The aging process: Major risk factor for disease and death. Proc. Natl. Acad. Sci. USA. 88: 53605363.

90. Hart, R.W., Setlow, R.B. (1974) Correlation between deoxyribonucleic acid excision repair and lifespan in a number of mammalian species. Proc. Natl. Acad. Sci. USA. 71 (6): 2169-2173.

91. Hauck, S., Bartke, A. (2000) Effects of growth hormone on hypothalamic catalase and $\mathrm{Cu} / \mathrm{Zn}$ superoxide dismutase. Free Rad. Biol. Med. 28:970-978.

92. Hauck, S., Bartke, A. (2001) Free radical defenses in the liver and kidney of human growth hormone transgenic mice: possible mechanisms of early mortality. J. Gerontology (Biol. Sci.), 56A: B153-B162.

93. Hayase, F., Nagaraj, R., Miyata, S., Njoroge, F., Monnier, V. (1989) Aging of proteins: Immunological detection of a glucose-derived pyrrole formed during Maillard reaction in vivo. J. Biol. Chem. 264: 3758-3764.

94. Hayflick, L. (1965) The limited in vitro lifetime of human diploid cel strains. Exp. Cell Res, 37: 614-636.

95. Hayflick, L. (1980) Recent advances in the biology of aging. Mech. Ageing Devel. 14: 59-79.

96. Hayflick, L. (1997) Mortality and immortality at the cellular level. A review. Biochemistry, 62 (11): 1180- 1190.

97. Hayflick, L., Morhead, P.S. (1961) The serial cultivation of human diploid cell strains. Exp. Cell Res. 25: 585-621.

98. Hayoz, D., Ziegler, T., Brunner, H.R., Ruiz, J. (1998) Diabetes Mellitus and vascular lesions. Metabolism. 12 (Suppl 1): 16-19.

99. Herreid, C.F. (1964) Bat longevity and metabolic rate. Exp Gerontol. 1:1-9.
100. Hofman, M.A. (1984) On the presumed coevolution of brain size and longevity in hominids. J. Human Evol., 13: 371-376.

101. Holloszy, J.O, Schechtman, K.B. (1991) Interactions between exercise and food restriction: effects on longevity of male rats. J. Appl. Physiol. 70: 1529-1535.

102. Horton, J.K., Baker, A., Berg, B.J., Sobol, R.W., Wilson, S.H. (2002) Involvement of DNA polymerase $B$ in protection against the cytotoxicity of oxidative DNA damage. DNA Repair, 1: 317-333.

103. Humphreys, J., Duyf, B., Joiner, M-L., Phillips, J., Hilliker, A. (1996) Genetic analysis of oxygen defense mechanisms in Drosophila melanogaster and identification of a novel behavioural mutant with a Shaker phenotype. Genome, 39: 749-757.

104. Ishikawa, T., Sakurai, J. (1986) In vivo studies on age dependency of DNA repair with age in mouse skin. Cancer Research, 46 (3): 1344-1348.

105. Itahana, K., Dimri, G., Campisi, J. (2001) Regulation of cellular senescence by p53. Eur. J. Biochem. 268: 2784-2791.

106. Jazwinski, S.M., Chen, J.B., Jeansonne, N.E. (1990) Replication control and differential gene expression in aging Yeast. In C.E Finch, T.E. Johnson (Eds.) Molecular Biology of Aging. Nova York: Wiley-Liss, 189-203.

107.Jazwinski, S.M. (1996) Longevity-assurance genes and mitochondrial DNA alterations: Yeast and Filamentous Fungi. In E.L. Schneider e J.W. Rowe (Eds.) Handbook of the Biology of Aging. San Diego: Academic Press, Inc., 3954.

108. Jazwinski, S.M. (1996) Longevity, genes, and aging. Science, 273: 54-59.

109.Jiang, C.H., Tsien, J.Z., Schultz, P.G., Hu, Y. (2001) The effects of aging on gene expression in the hypothalamus and cortex of mice. PNAS, 98 (4): 1930-1934.

110.Ji, L.L. (1993) Antioxidant enzyme response to exercise and aging. Med. Sci. Sports Exerc. 25 (2): 225-231.

111.Ji, L.L. (1995) Oxidative stress during exercise: implications of antioxidant nutrients. Free Rad. Biol. Med. 18(6): 1079-1086.

112.Ji, L.L. (1999) Antioxidants and oxidative stress in exercise. P.S.E.B.M., 222: 283-292.

113. Ji, L.L,, Stratman, F., Lardy, H. (1988) Enzimatic down regulation with exercise in rat skeletal muscle. Arch. Biochem. Biophys. 263: 137-149.

114. Johnson, K.A. (1993) Conformational coupling in DNA polymerase fidelity. Annu. Rev. Biochem. 62: 685-713.

115. Johnson, S.A,, Finch, C.E. (1996) Changes in gene expression during brain aging: A survey. In E.L. Schneider e J.W. Rowe (Eds.) Handbook of the Biology of Aging. San Diego: Academic Press, Inc., 300-327.

116. Jourd'heuil, D., Kang, D., Grisham, M. (1997) Interactions between superoxide and nitric oxide: implications in DNA damage and mutagenesis. Frontiers in Bioscience, 2: d189196.

117. Kappus, H. (1985) Lipid Peroxidation: Mechanisms, analysis, enzymology and biological relevance. In H. Sies (Ed.) Oxidative Stress. Londres: Academic Press, 273-310.

118. Kihlstrom, M.T. (1990) Protection effect of endurance training against reoxygenaion-induced injuries in rat heart. $J$. Appl. Physiol. 68: 1672-1678. 
119. Kihlstrom, M.T. (1992) Lipid peroxidation capacities in the myocardium of endurance-trained rats and ice in vitro. Acta Physiol. Scand. 146: 177-183.

120. Kretzschmar, B., Klinger, W. (1990) The hepatic glutathione system - influence of xenobiotics. Exp. Pathol. 38: 14564.

121. Ku, H., Brunk, U.T., Sohal, R.S. (1993) Relationship between mitochondrial superoxide and hydrogen peroxide production and longevity of mammalian species. Free Rad. Biol. Med. 15: 621-627.

122. Kuck, J., Yu, N., Askren, C. (1982) Total sulfhydryl by Raman spectroscopy in the intact lens of several species: variation in the nucleus and along optical axis during aging. Exp. Eye Res., 34: 23-37.

123. Kurenova, E.V., Mason, J.M. (1997) Telomere functions. A review. Biochemistry, 62 (11): 1242-1253.

124. Laires, M.J., Monteiro, C.P., Ferreira, A.M. (2001) Stress oxidativo: papel dos micronutrientes antioxidantes. Rev. Port. Med. Desp. 19: 43-62.

125. Lakowski, B., Hekimi, S. (1996) Determination of lifespan in Caenorhabditis elegans by four clock genes. Science. 272: 1010-1013.

126. Lal, S.B., Ramsey, J.J., Monemdjou, S., Weindruch, R., Harper, M. (2001) Effects of caloric restriction on skeletal muscle mitochondrial proton leak in aging rats. $J$. Gerontology (Biol. Sci.), 56A (3): B116-B122.

127. Lambert, B., Ringborg, U., Skoog, L. (1979) Age-related decrease of ultraviolet light-induced DNA repair synthesis in human peripheral leucocytes. Cancer Research, 39 (7): 2792-2795.

128. Larsen, P.L. (1993) Aging and resistance to oxidative damage in Caenorhabditis elegans. Proc. Natl. Acad. Sci. USA, 90: 8905-8909.

129. Lawler, J., Powers, S., Visser, T., Dijk, H., Kordus, M., Ji, L. (1993) Acute exercise and skeletal muscle antioxidant and metabolic enzymes: effects of fiber type and age. Am. J. Physiol. 34: R1344-R1350.

130. Lawler, J., Powers, S. (1999) Oxidative stress, antioxidant status, and the contracting diaphragm. Can. J. Appl. Physiol. 2 (1): 23-55.

131. Lee, A., Cerami, A. (1990) Modifications of proteins and nucleic acids by reducing sugars: possible role in aging. In E.L. Schneider e J.W. Rowe (Eds.) Handbook of the Biology of Aging. San Diego: Academic Press, 116-130.

132. Leeuwenburgh, C., Fiebig, R., Chandwaney, R., Ji, L.J. (1994) Aging and exercise training in skeletal muscle: responses of glutathione and antioxidant enzyme systems. Am. J. Physiol. 267: R439-R445.

133. Leeuwenburgh, C., Ji, L.L. (1996) Alteration of glutathione and antioxidant status in unfed and refed rats. Journal Nutriton, 126: 1833-1843.

134. Leeuwenburgh, C., Hansen, P., Shaish, A., Holloszy, J.O, Heinecke, J.W. (1998) Makers of protein oxidation by hydroxyl radical and reactive nitrogen species in tissues of aging rats. Am. J. Physiol. 274: R453-R461.

135. Leeuwenburgh, C., Heinecke, J.W. (2001) Oxidative stress and antioxidants in exercise. Current Medical Chemistry, 8: 829-838.

136. Lenaz, G. (1998) Role of mitochondria in oxidative stress ang ageing. Biochem. Biophys. Acta. 1366: 53-67.
137. Levin, E.R. (2001) Invited review: Cell localization, physiology, and nongenomic actions of estrogen receptors. J. Appl. Physiol. 91: 1860-1867.

138. Levine, R.L., Stadtman, E.R. (1996) Protein modification with aging. In E.L. Schneider e J.W. Rowe (Eds.) Handbook of the Biology of Aging. San Diego: Academic Press, Inc., 184-197.

139. Lexell, J. (1993) Ageing and human muscle: Observations from Sweden. Can. J. Appl. Phys. 18: (1) 2-18.

140. Lezza, A.M., Mecocci, P., Cormio, A., Beal, M.F., Cherubini, A., Cantatore, P., Senin, U., Gadaleta, M.N. (1999) Mitochondrial DNA 4977 bp deletion and OH8dG levels correlate in the brain of aged subjects but not Alzheimer's disease patients. FASEB J. 13: 1083-1088.

141. Lithgow, G.J. (1996) Molecular genetics of Caenorhabditis elegans aging. In E.L. Schneider e J.W. Rowe (Eds.) Handbook of the Biology of Aging. San Diego: Academic Press, Inc., 55-73.

142. Lithgow, G.J., Kirkwood, T.B. (1996) Mechanisms and evolution of aging. Science, 273: 83.

143. Loeb, J., Northrup, J.H. (1916) Is there a temperature coefficient for the duration of life? Proc. Natl. Acad. Sci. 2: 456-457.

144. Loeb, J., Northrup, J.H. (1917) On the influence of food and temperature upon the duration of life? J. Biol. Chem. 32: $102-121$.

145. Macieira-Coelho, A. (1970) The decreased growth potential in vitro of human fibroblasts of adult origin. In E. Holecková, V.J. Cristofalo (Eds.)Aging in Cell and Tissue Culture, Londres: Plenum Press, 121-132.

146. Mackay, W.J., Orr, W.C., Bewley, G.C. (1990) Genetic and molecular analysis of antioxidant enzymes in Drosophila melanogaster: A correlation between catalase activity levels, life span, ans spontaneous mutation rate. In C.E. Finch, T.E. Johnson (Eds.) Molecular Biology of Aging. New-York: Wiley-Liss, 157-170.

147. Magalhães, M.M. (1994) Peroxissomas. In C. Azevedo (Ed.) Biologia Celular. Porto: LIDEL, 299-304.

148. Martin, G.M., Hoehn, H., Norwood, T.H. (1980) Genetic, development and gerontological aspects of disease. In R.B. Hil \& M.F. LaVia (Eds.) Principles of Pathobiology. New York: Oxford University Press, 287-347.

149. Martin, G.M., Oshima, J. (2000) Lessons from human progeroid syndromes. Nature, 408: 263-266.

150. Marx, J. (1994) Chromossome ends catch fire. Science. 265 : 1656-1658.

151. Mattison, J., Wright, J., Bronson, R., Roth, G., Ingram, D., Bartke, A. (2000) Studies of aging in Ames dwarf mice: effects of caloric restriction. J. Am. Aging Assoc. 23: 9-16.

152. May, J.M. (1999) Is ascorbic acid an antioxidant for the plasma membrane? FASEB J. 13: 995-1006.

153. McGue, M., Vaupel, J., Holm, N., Harvald, B. (1993) Longevity is moderately heritable in a sample of Danish twins born 1870-1890. J. Gerontology (Biol. Sci.), 48: B237B244.

154. Medvedev, Z. (1990) An attempt at rational classification of theories of ageing. Biol. Rev. 65: 375-398.

155. Meister, A. (1992) Commentary: On the antioxidant effects of ascorbic acid and glutathione. Biochem. Pharmac. 44 (10): 1905-1915.

156. Meites, J. (1990) Effects of aging on the hypothalamicpituitary axis. Rev. Biol. Res. Aging, 4: 253-261. 
157. Melov, S., Coskun, P., Patel, M., Tuinstra, R., Cottrell, B., Jun, A.S., Zastawny, T.H., Dizdaroglu, M., Goodman, S.I., Huang, T., Miziorko, H., Epstein, C.J., Wallace, D. (1999) Mitochondrial disease in superoxide dismutase 2 mutant mice. Proc. Natl. Acad. Sci. USA, 96: 846-851.

158. Melov, S. , Ravenscroft, J., Malik, S., Gill, M.S., Walker, D.W., Clayton, P.E., Wallace, D., Malfroy, B., Doctrow, S.R., Lithgow, G.J. (2000) Extension of life-span with superoxide dismutase/catalase mimetics. Science, 289: 1567-1569.

159. Migliaccio, E., Giorgio, M., Mele, S., Pelicci, G., Reboldi, P., Pandolfi, P.P., Lanfrancone, L., Pelicci, P.G. (1999) The p66shc adaptor protein controls oxidative stress response and life span in mammals. Nature, 402: 309-313.

160. Miller, R.A. (1994) The Biology of Aging and Longevity. In W.R. Hazzard, E.L. Bierman, J.P. Blass, W. Ettinger Jr, J.B.Halter (Eds.) Principles of Geriatric Medicine and Gerontology. Londres: McGraw-Hill, Inc., 3-18.

161. Miller, R.A. (1996) The aging immune system: primer and prospectus. Science. 273: 70-74.

162. Miller, R.A. (1996) Aging and immune response. In E.L. Schneider e J.W. Rowe (Eds.) Handbook of the Biology of Aging. San Diego: Academic Press, Inc., 355-392.

163. Miller, R.A. (2001) Biomarkers of aging: prediction of longevity by using age-sensitive T-cell subset determinations in a middle-aged, genetically heterogeneous mouse population. J. Gerontology (Biol. Sci.), 56A (4):B180-B186.

164. Mockett, R.J., Sohal, R.S. (1997) Oxidative stress may be a casual factor in senescence of animals. In J.M. Robine, M. Allard, J.W.Vaupel (Eds.) Longevity: to the limits and beyond. New York: Springer-Verlag,139-154.

165. Monnier, V. (1990) Nonenzymatic glycosilation, the Maillard reaction and the aging process. J. Gerontology, 45: B105.

166. Monnier, V., Cerami, A. (1981) Nonenzymatic browning in vivo: possible process for aging of long-lived proteins. Science, 211: 491-493.

167. Morrison, N.A., Qi, J.C., Tokita, A., Kelly, P.J., Crofts, L., Nguyen, T.V., Sambrook, P.N., Eisman, J.Á. (1994)

Prediction of bone density from vitamin D receptor alleles. Nature, 367: 284-287.

168. Mota, M.P. (2003) Influência genética e estocástica no fenómeno de envelhecimento: Repercussões do nível de actividade física no stresse oxidativo e na longevidade em Drosophila melanogaster. Dissertação de Doutoramento. UTAD, Vila Real (não publicado).

169. Mortenson, H., Volund, A., Christopherson, C. (1984) Glucosylation of human haemoglobin A. Dynamic variation in $\mathrm{HbA}_{1 \mathrm{c}}$ described by a biokinetic model. Clin. Chem. Acta, 136: 75-81.

170. Mu, J., Wei, L.X. (2002) Telomere and telomerase in oncology. Cell Research, 12 (1): 1-7.

171. Mueller, L. (1987) Evolution of accelerated senescence in laboratory populations of Drosophila. Proc. Natl. Acad. Sci. USA, 84: 1974-1977.

172. Mueller, S.N., Rose, E.M., Levine, E.M. (1980) Cellular senescence in a cloned strain of bovine fetal aortic endothelial cells. Science. 207: 889-891.

173. Muscari, C., Giaccari, A., Giordano, E., Clo', C., Guarnieri, C., Caldarera, C.M. (1996) Role of reactive oxygen species in cardiovascular aging. Mol Cell Biochem 160/161:159-166.
174. Nicholls, K., Mandel, T. (1989) Advanced glycosilation end-products in experimental murine diabetic nephropathy: effect of islet isografting and of aminoguanidine. Lab. Invest. 61: 486-491.

175. Nicholls, D.G., Budd, S.L. (2000) Mitochondria and neuronal survival. Physiol. Rev. 83: 315-360.

176. Nohl, H., Hegner, D. (1978) Do mitochondria produce oxygen radicals in vivo? Eur. J. Biochem. 82: 563-567.

177. Nouspikel, T., Hanawalt, P.C. (2002) DNA repair interminally differentiated cells. DNA Repair, 1: 59-75.

178. Ohkusu-Tsukada, K., Tsukada, T., Isobe, K. (1999) Accelerated development and aging of the immune system in p53-deficient mice1. J. Immunology, 163: 1966-1972.

179. Ohneda, K., Ulshen, M.H., Fuller, C.R., Dercole, A.J., Lund, P.K. (1997) Enhanced growth of small bowel in transgenic mice expressing human insulin-like growth factor I. Gastroenterology, 112: 444-454.

180. Orgel, L.E. (1963) The maintenance of accuracy of protein synthesis and its relevance to agins. Proc. Natl. Acad. Sci. USA, 49: 512-517.

181. Orr, W.C., Sohal, R.S. (1994) Extension of life-span by overexpression of superoxide dismutase and catalase in Drosophila melanogaster. Science. 263: 1128-1130.

182. Papaconstantinou, J., Reisner, P.D., Liu, L. (1996) Mechanisms of altered gene expression with aging. In W.R. Hazzard, E.L. Bierman, J.P. Blass, W. Ettinger Jr, J.B.Halter (Eds.) Principles of Geriatric Medicine and Gerontology. New York: McGraw-Hill, Inc., 150-183.

183. Parkes, T.L., Hilliker, A.J., Phillips, J.P. (1993) Genetic and biochemical analysis of glutatione-S-transferase in the oxygen defense system in Drosophila melanogaster. Genome, 36: 1007-1014.

184. Park, J., Floyd, R.A. (1992) Lipid peroxidation products mediate the formation of 8-hydroxyguanosine in DNA. Free Rad. Biol. Med. 12: 245-250.

185. Patel, S., Wong, I., Johnson, K. (1991) Pre-steady-state kinetic analysis of processive DNA replication including complete characterization of an exonuclease-deficient mutant. Biochemistry, 30: 51-525.

186. Patrick, J.S., Thorpe, S.R., Baynes, J.W. (1990) Nonenzymatic glycosylation of protein does not increase with age in normal human lenses. J. Gerontology, 45: B18B23.

187. Pawelec, G., Remarque, E., Barnett, Y., Solana, R. (1998) T cells and aging. Frontiers in Bioscience, 3: d59-d99.

188. Pearl, R. (1928) The rate of living. New York: Knopf.

189. Pero, R.W., Anderson, M.W., Doyle, G.A., Anna, C.H., Romagna, F., Markowitz, M., Bryngelson, C. (1990) Oxidative stress induces DNA damage and inhibits the repair of DNA lesions induced by N-Acetoxy-2Acetylaminofluorene in human peripheral mononuclear leucocyte. Cancer Research, 50 (15): 4619-4625.

190. Phaneuf, S., Leeuwenburgh, C. (2001) Apoptosis and exercise. Med. Sci. Sports Exerc. 33 (3): 393-396.

191. Pollack, M., Leeuwenburgh, C. (1999) Exercise traininginduced alterations in skeletal muscle antioxidant capacity: a brief review. Med. Sci. Sports Exerc. 31(7): 987-997.

192. Pollack, M., Leeuwenburgh, C. (1999) Molecular mechanisms of oxidative stress in aging: free radicals, aging, antioxidants and disease. In C.K. Sen, L. Packer, O. Hãnninen (Eds) Handbook of Oxidants and Antioxidants in Exercise. London: Elsevier Science, 881-923. 
193. Pollack, M., Leeuwenburgh, C. (2001) Apoptosis and aging: role of the mitochondria. J. Gerontology (Biol. Sci.), 56A (11): B475-B482.

194. Pollack, M., Phaneuf, S., Dirks, A., Leeuwenburgh, C. (2002) The role of apoptosis in the normal aging brain, skeletal muscle, and heart. Ann N. Y. Acad. Sci. 959: 93107.

195. Powers, S., Criswell, D., Lawler, J., Ji, L.L., Martin, D., Herb., R., Dudley, G. (1994) Influence of exercise and fiber type on antioxidant enzyme activity in rat skeletal muscle. Am. J. Physiol. 266: R375-R380.

196. Powers, S.K., Ji, L.L., Leeuwenburgh, C. (1999) Exercise training-induced alterations in skeletal muscle antioxidant capacity: a brief review. Med. Sci. Sports Exerc. 31 (7): 987997.

197. Pryor, W.A. (1986) Oxy-radicals and related species: their formation, lifetimes, and reactions. Ann. Rev. Physiol. 48: 657.

198. Pyke, S., Quintanilha, A. (1986) Severe depletion in liver glutathione during physical exercise. Biochem. Biophys. Res. Comun. 139: 926-931.

199. Pyke, S., Lew, H., Quintanilha, A. (1986) Severe depletion in liver glutathione during physical exercise. Biochem. Biophys. Res. Comun., 139: 926-931.

200. Reed, D.J. (1990) Glutathione: toxicological implications. Ann. Rev. Pharmacol. Toxicolo. 30: 603-631.

201. Requena, J.R. , Chao, C. , Levine, R. , Stadtman, E.R. (2001) Glutamic and aminoadipic semialdehydes are the main carbonyl products of metal-catalyzed oxidation of proteins. Proc. Natl. Acad. Sci. USA, 98 (1): 69-74.

202. Richter, C., Park, J.W., Ames, B.N. (1988) Normal oxidative damage to mitochondrial and nuclear DNA is extensive. Proc. Natl. Acad. Sci. USA, 85: 6465-6467.

203. Robertis, E.D., Robertis, E.M. (1987) Biologia celular e molecular. Lisboa: Fundação Calouste Gulbenkian,.

204. Robbins, S.L. (1974) Patologia estrutural e functional. Rio de Janeiro: Interamericana.

205. Röhme, D. (1981) Evidence for a relationship between longevity of mammalian species and life spans of normal fibroblasts in vitro and erythrocytes in vivo. Proc. Natl. Acad. Sci. USA, 78 (8): 5009-5013.

206. Rose, M.R. (1991) Evolutionary Biology of Aging. Oxford: Oxford University Press.

207. Rudolph, K., Chang, S., Lee, H-W, Blasco, M., Gottlieb, G., Greider, C., DePinho, R. (1999) Longevity, stress response, and cancer in aging telomerase-deficient mice. Cell, 96: 701-712.

208. Ryu, A, Itabe, H., Mutoh, M., Kudo, I., Arai, H., Inoue, K. (2000) Enhanced degradation of phospholipids by phospholipase A2 in liver of carbon tetrachloride-treated rat. Journal of Health Science, 46 (4): 275-281.

209. Sacher, G. (1977) Life table modification and life prolongation. In C.E. Finch e L. Hayflick (Eds.), Handbook of the Biology of Aging, 1a edição. New York: Van Nostrand., 582638.

210. Sankarapandi, S., Zweier, J.L. (1999) Bicarbonate is required for the peroxidase function of $\mathrm{Cu}, \mathrm{Zn}$-Superoxide dismutase at physiological pH. J. Biol. Chem. 274 (3): 12261232.

211.Sarkar, D.K., Hentges, S., De, A., Reddy, R. (1998) Hormonal control of pituitary prolactin-secreting tumors. Frontiers in Bioscience, 3: d934-d943.
212. Sauer, H., Wartenberg, M., Hescheler, J. (2001) Reactive oxygen species as intracellular messengers during cell growth and differentiation. Cell. Physiol. Biochem. 11: 173186.

213. Sen, C.K. (1995) Oxidants and antioxidants in exercise. J. Appl. Physiol., 79 (3): 675-686.

214. Sen, C.K. (2001) Antioxidants in exercise nutrition. Sports Med., 31 (13): 891-908.

215. Sen, C.K., Atalay, M., Hänninen, O. (1992) Skeletal muscle and liver glutathione homeostasis in response to training, exercise, and immobilization. J. Appl. Physiol. 73(4): 1265-1272.

216. Shadel, G.S., Clayton, D.A. (1997) Mitochondrial DNA maintenance in vertebrates. Annu. Rev. Biochem. 66: 409435.

217. Sherr, C.J., DePinho, R.A. (2000) Cellular senescence: mitotic clock or culture shock? Cell, 102: 407-410.

218. Shigenaga, M.K., Hagen, T.M., Ames, B.N. (1994) Oxidative damage and mitochondrial decay in aging. Proc. Natl. Acad. Sci. USA, 91: 10771-10778.

219. Sies, H. (1985) Oxidative Stress: Introductory Remarks. In H. Sies (Ed.) Oxidative Stress. Londres: Academic Press, 18.

220. Sies, H. (1997) Physiological society symposium: impaired endothelial and smooth muscle cell function in oxidative stress. Oxidative Stress: Oxidants and antioxidants. Experimental Physiology. 82: 291-295.

221. Smith, P.J., Tappel, A.L., Chow, C.K. (1974) Glutathione Peroxidase activity as a function of dietary selenomethionine. Nature, 247: 392-393.

222. Smith, M.T., Evans, C.G., Thor, H., Orrenius, S. (1985) Quinone-induced oxidative injury to cells and tissues. In H. Sies (Ed.) Oxidative Stress. Londres: Academic Press, 91113.

223. Smith, C.D., Carney, J.M., Starke-Reed, P.E., Oliver, C.N., Stadtman, E.R., Floyd, R.A., Markesbery, W.R. (1991) Excess brain protein oxidation and enzyme dysfunction in normal aging and in Alzheimer disese. Proc. Natl. Acad. Sci. USA, 88: 10540-10543.

224. Smith, G.S., Walford, R.L. (1977) Influence of the main histocompatibility complex on ageing in mice. Nature. 270: 727-729.

225. Sohal, R.S. (1993) The free radical hypothesis of aging: An appraisal of the current status. Aging Clin. Exp. Res. 5: 317.

226. Sohal, R.S. (1997) Role of mitochondria and oxidative stress in the aging process. In M.F. Beal, N. Howell e I. Bodis-Wollner (Eds) Mitochondria and Free Radicals in Neurodegenerative Diseases. New York: Wiley-Liss, 91-107.

227. Sohal, R.S., Arnold, L.A., Sohal, B.H. (1990) Age-related changes in antioxidant enzymes and prooxidant generation in tissues of the rat with special reference to parameters in two insect's species. Free Rad. Biol. Med. 10: 495-500.

228. Sohal, R.S., Agarwal, S., Dubey, A., Orr, W.C. (1993) Protein oxidative damage is associated with life expectancy of houseflies. Proc. Natl. Acad. Sci. USA. 90: 7255-7259.

229. Sohal, R.S., Dubey, A. (1994) Mitochondrial oxidative damage, hydrogen peroxide release, and aging. Free Rad. Biol. Med. 16. 5: 621-626.

230. Sohal, R.S., Sohal, B.H. (1991) Hydrogen peroxide release by mitochondria increases during aging. Mech. Ageing Dev. 57: 187-202. 
231. Sohal, R.S., Agarwal, A., Agarwal, S., Orr, W.C. (1995) Simultaneous overexpression of $\mathrm{Cu}, \mathrm{Zn}$ superoxide dismutase and catalase retards age related oxidative damage and increases metabolic potential in Drosophila melanogaster. J. Biol. Chem. 270: 20224-20229.

232. Sohal, R.S, Sohal, B.H., Orr, W.C. (1995) Mitochondrial superoxide and hydrogen peroxide generation, protein oxidative damage, and longevity in different species of flies. Free Rad. Biol. Med. 19: 499-504.

233. Sohal, R.S., Weindruch, R. (1996) Oxidative stress, caloric restriction, and aging. Science. 273: 59-63.

234. Sonntag, W.E., Lynch, C.D., Cefalu, W.T., Ingram, R.L., Bennett, S.A., Thornton, P.L., Khan, A.S. (1999) Pleiotropic effects of Growth hormone and insulin-like growth factor (IGF)-1 on biological aging: Inferences from moderate caloric- restricted animals. J. Gerontology (Biol. Sci.). 54A. 12: B521-B538.

235. Spector, I.M. (1974) Animal longevity and plasma turnover rate. Nature, 240: 66.

236. Squier, T.C., Bigelow, D.J. (2000) Protein oxidation and age-dependent alterations in calcium homeostasis. Frontiers in Biosciences, 5: D504-D526.

237. Stadtman, E.R. (1992) Protein oxidation with aging. Science. 257: 1220-1224.

238. Stadtman, E.R. (1993) Oxidation of free amino acids and amino acid residues in proteins by radiolysis and by metalcatalyzed reactions. Annu. Rev. Biochem. 62: 797-821.

239. Starke-Reed, P.E., Oliver, C.N. (1989) Protein oxidation and proteolysis during aging and oxidative stress. Arch. Biochem. Biophys. 275: 559-567.

240. Starke-Reed, P.E., Oliver, C.N. (1991) Metal-catalyzed oxidation of proteins. J. Biological Chemistry, 266 (4): 20052008.

241. Stein, G.H., Beenson, M., Gordon, L. (1990) Failure to phosphorylate the retinoblastoma gene product in senescent huma fibroblasts. Science. 247: 666-669.

242. Steinberg, J.J., Passman, R., Scicutella, A, Gleeson, J., Davies, P. (1990) Alteration of DNA repair in neurodegenerative diseases of aging. In C.E. Finch, T.E. Johnson (Eds.) Molecular Biology of Aging. Nova York: Wiley-Liss, 53-65.

243. Sun, J., Tower, J. (1999) FLP recombinase-mediated induction of $\mathrm{Cu} / \mathrm{Zn}$-superoxide dismutase transgene expression can extend the life span of adult Drosophila melanogaster flies. Mol. Cell Biol., 19: 216-218.

244. Szilard, L. (1959) On the nature of the aging process. Proc. Natl. Acad. Sci. USA, 45: 30-45.

245. Tatar, M., Khazaeli, A.A., Curtsinger, J.W. (1997) Chaperoning extended life. Nature, 390: 30.

246. Taub, J., Lau, J., Ma, C., Hahn, J., Hoque, R., Rothblatt, J., Chalfie, M. (1999) A cytosolic catalase is needed to extend adult lifespan in C. elegans daf-c and clk-1 mutants. Nature, 399: 162-166.

247. Taylor, A.W., Noble, E.G., Cunningham, D.A., Paterson, D.H., Rechnitzer, P. (1992) Ageing, skeletal muscle contractile properties and enzyme activities with exercise. In Y. Sato, J. Poortmans, I. Hashimoto, Y. Oshida (Eds.) Integration of Medical and Sports Sciences (vol. 37). Med. Sport Sci. Basel: Karger, 109-125.

248. Tedesco, P.M., Link, C.D, Hutchison, E.W., Johnson, T.E. (1990) Cloning a gene for life-extension in Caenorhabditis elegans. In C.E Finch, T.E. Johnson (Eds.) Molecular Biology of Aging. Nova York: Wiley-Liss, 3-17.

249. Terry, L.C., Halter, J.B. (1994) Aging of the endocrine system. In W.R. Hazzard, E.L. Bierman, J.P. Blass, W. Ettinger Jr, J.B.Halter (Eds.) Principles of Geriatric Medicine and Gerontology. New York: McGraw-Hill, Inc., 791-805.

250. Thayer, R.E., Rice, C.L., Pettigrew, F.P., Noble, E.G., Taylor, A.W. (1993) The fibre composition of skeletal muscle. In J.R. Poortmans (Ed.) Principles of Exercise Biochemistry (vol. 38) Med. Sport Sci. Basel: Karger, 25-50.

251. Thomas, J.A., Mallis, R.J. (2001) Aging and oxidation of reactive oxygen sulphydryls. Exp. Gerontol. 36 (9): 15191526.

252. Tolmasoff, J.M., Ono, T., Cutler, R.G. (1980) Superoxide dismutase: Correlation with life/span and specific metabolic rate in primate species. Proc. Natl. Acad. Sci. USA, 77 (5): 2777-2781.

253. Torre, R., Casado, A., López-Fernandez, M.E., Carrascosa, D., Venarucci, D. (1999) Superoxide dismutase activity levels in a Spanish population 50-93 years. Am. J. Human Biol, 11: 45-47.

254. Toshinai, K., Oh-ishi, S., Kizaki, T., Ookawara, T., Haga, S., Ohno, H. (1997) Effect of swimming training on antioxidant enzymes in kidney of young and old mice. Res. Comm. In Molecular Pathology and Pharm., 95 (3): 259-274.

255. Totter, J.R. (1980) Spontaneous cancer and its possible relationship to oxygen metabolism. Proc. Natl. Acad. Sci. USA. 77 (4): 1763-1767.

256. Tsurudome, Y., Hirano, T., Hirata, K., Higure, A., Nagata, N., Takahashi, K., Itoh, H., Kasai, H. (2001) Age-associated increase of 8-hydroxydeoxyguanosine in human colorectal tissue DNA. J. Gerontology (Biol. Sci.), 56A (11): B483-B485.

257. Uhlig, S., Wendel, A. (1992) The physiological consequences of glutathione variations. Life Sciences, 51: 1083-1094.

258. Umminger, B.L. (1975) Body size and whole blood sugar concentration in mammals. Comp. Biochem. Physiol. 52A: 455-458.

259. Vandervoort, A.A., Symons, T.B. (2001) Functional and metabolic consequences of sarcopenia. Can. J. Appl. Physiol. 26 (1): 90-101.

260. Vanfleteren, J.R. (1993) Oxidative stress and ageing in Caenorhabditis elegans. Biochemistry J. 292: 605-608.

261. Vasilaki, A., Iwanejko, L., McArdle, F., Jackson, M.J., McArdle, A. (2002) Mechanisms responsible for attenuated adaptive responses in skeletal muscle of aged mice following contractile activity. J. Physiol. 543P: 100P

262. Vettraino, J., Buck, S., Arking, R. (2001) Direct selection for paraquat resistance in Drosophila results in a different extended longevity phenotype. J. Gerontology (Biol. Sci.), 56A: B415-B425.

263. Vittorini, S., Paradiso, C., Donati, A. , Cavallini, G. , Masini, M. , Gori, Z. , Pollera, M. , Bergamini, E. (1999) The age-related accumulation of protein carbonyl in rat liver correlates with age-related decline in liver proteolitic activities. J. Gerontology (Biol. Sci.), 54A (8): B318-B323

264. Vlassara, H. (1990) Advanced non-enzymatic tissue glycosylation: mechanism implicated in complications associated with aging. In C.E Finch, T.E. Johnson (Eds.) Molecular Biology of Aging. Nova York: Wiley-Liss, 171-185.

265. Vlassara, H., Brownlee, M., Cerami, A. (1986) Novel macrophage receptor for glucose-modified proteins is dis- 
tinct from previous described scavenger receptors. J. Exp. Med. 164: 1301-1309.

266. Vogel, E.W., Nivard, M.J., Zijlstra, J.A. (1991) Variation of spontaneous and induced mitotic recombination in different Drosophila populations: a pilot study on the effects of polyaromatic hydrocarbons in six newley constructed tester strains. Mut. Res. 250: 291-298.

267. Vogel, E.W., Nivard, M.J. (2001) Phenotypes of Drosophila homologs of human XPF and XPG to chemically-induced DNA modifications. Mutat. Res. 476 (1-29: 149-165.

268. Walford, R.L. (1969) The immunological theory of aging. Stanford: Williams \& Wilkins.

269. Walford, R.L. (1990) The major histocompatibility complex and aging in mammals. In C.E Finch, T.E. Johnson (Eds.), Molecular Biology of Aging. Nova York: Wiley-Liss, 31-41.

270. Wallace, D.C. (1992) Mitochondrial genetics: A paradigm for aging and degenerative diseases? Science. 256: 628-632.

271. Wallace, D.C. (1999) Mitochondrial diseases in Man and Mouse. Science, 283: 1482-1487.

272. Wallace, D.C., Ye, J., Neckelmann, S., Singh, G., Webster K., Greenberg, B. (1987) Sequence analysis of cDNAs for the human and bovine ATP synthase beta sub-unit: mitochondrial DNA genes sustain seventeen times more mutations. Current Genetics, 12: 12-90.

273. Wang, W., Ballatori, N. (1998) Endogenous glutathione conjugates: occurence and biological functions. Pharmacol. Rev. 50 (3): 335-356.

274. Wei, H., Ca, Q., Rahn, R., Zhang, X., Wang, Y. , Lewohl, M. (1998) DNA structural integrity and base composition affect ultraviolet light-induced oxidation DNA damage. Biochemistry, 37: 6485-6490.

275. Weindrunch, R., Sohal, S.R. (1997) Caloric intake and aging. New Eng. J. Med. 337: 986-994.

276. Wells, C.L. (1991) Women, Sport \& Performance: A physiological perspective. Champaign, Il: Human Kinetics.

277. Wheller, J.C., Bieschke, E.T., Tower, J. (1995) Muscle-specific expression of drosophila HSP70 in response to aging and oxidative stress. Proc. Natl. Acad. Sci. USA, 92: 1040810412.

278. Wise, P.M., Krajnak, K.M., Kashon, M.L. (1996) Menopause: the aging of multiple pacemakers. Science. 273: 67-70.

279. Wong, I., Patel, S., Johnson, K. (1991) An induced-fit kinetic mechanism for DNA replication fidelity: direct measurement by single-turnover kinetics. Biochemistry, 30: 526537.

280. Wood, R.D. (1996) DNA repair in eukaryotes. Annu. Rev. Biochem, 65: 135-167.

281. Woodhead, A.D., Setlow, R.B., Grist, E. (1980) DNA repair and longevity in three species of cold-blooded vertebrates. Exp. Gerontol. 15: 301-304.

282. Youngman, L.D., Park, J., Ames, B.N. (1992) Protein oxidation associated with aging is reduced by dietary restriction of protein or calories. Proc. Natl. Acad. Sci. USA, 89: 9112-9116.

283. Yu, B.P (1994) Cellular defenses against damage from reactive oxygen species. Physiology Review, 74: 139-162.

284. Yu, B.P. (1996) Aging and oxidative stress: Modulation by dietary restriction. Free Rad. Biol. Med. 21. 5: 651-668. 